\title{
Sovereign Debt Restructurings
}

\author{
By Maximiliano Dvorkin, Juan M. Sánchez, \\ Horacio SAPRIZA, AND EMIRCAN YURDAGUL *
}

\begin{abstract}
Sovereign debt crises involve debt restructurings characterized by a mix of face value haircuts and maturity extensions. The prevalence of maturity extensions has been hard to reconcile with economic theory. We develop a model of endogenous debt restructuring that captures key facts of sovereign debt and restructuring episodes. While debt dilution pushes for negative maturity extensions, three factors are important in overcoming the effects of dilution and generating maturity extensions upon restructurings: income recovery after default, credit exclusion after restructuring, and regulatory costs of book value haircuts. We employ dynamic discrete choice methods that allow for smoother decision rules, rendering the problem tractable. (JEL E44, F34, F41, H63)
\end{abstract}

$\mathrm{D}^{\mathrm{s} n}$ ebt restructurings are a salient feature of sovereign defaults. We present new empirical evidence showing that restructuring operations very often involve the maturity extension of the original debt instruments. We then develop a quantitative small open economy model of sovereign debt, maturity choice, default, and restructuring that not only captures the business cycle behavior of key debt statistics but, crucially, also mimics the debt, maturity, and payment dynamics observed around distressed debt restructurings. To quantitatively solve the model, we develop a discrete choice method used in the labor literature that simplifies the problem substantially and may be useful in future research on debt maturity choice. We summarize the most significant contributions of the paper as follows: it (i) provides evidence on maturity extensions in restructurings, (ii) improves our understanding of restructurings by providing a quantitative model of sovereign debt in which defaults are

\footnotetext{
* Dvorkin: Federal Reserve Bank of St. Louis, One Federal Reserve Bank Plaza, St. Louis, MO 63102 (email: maximiliano.a.dvorkin@stls.frb.org); Sánchez: Federal Reserve Bank of St. Louis, One Federal Reserve Bank Plaza, St. Louis, MO 63102 (email: juan.m.sanchez@stls.frb.org); Sapriza: Board of Governors of the Federal Reserve System, Constitution Ave NW \& 20th Street Northwest, Washington, DC 20551 (email: horacio.sapriza@ frb.gov); Yurdagul: Universidad Carlos III de Madrid, Calle Madrid, 126 Getafe-Spain 28903 (email: emircan. yurdagul@uc3m.es). Simon Gilchrist was coeditor for this article. The views expressed in this paper are those of the authors and do not necessarily reflect those of the Federal Reserve Bank of St. Louis, the Board of Governors, or the Federal Reserve System. We thank Manuel Amador, Cristina Arellano, Javier Bianchi, Paco Buera, Satyajit Chatterjee, Hal Cole, Dean Corbae, Bill Dupor, Juan Carlos Hatchondo, Berthold Herrendorf, Fernando Leibivici, Rody Manuelli, Leo Martinez, Gabriel Mihalache, Alex Monge-Naranjo, Juampa Nicolini, Paulina RestrepoEchevarria, Cesar Sosa-Padilla, Mark Wright, Vivian Yue, and seminar and conference participants for useful conversations and comments. Asha Bharadwaj, HeeSung Kim, and Ryan Mather provided excellent research assistance. Yurdagul gratefully acknowledges the support from the Ministerio de Economía y Competitividad (Spain) (ECO2015-68615-P), María de Maeztu grant (MDM 2014-0431), and from Comunidad de Madrid, MadEco-CM (S2015/HUM-3444).

${ }^{\dagger}$ Go to https://doi.org/10.1257/mac.20190220 to visit the article page for additional materials and author disclosure statement(s) or to comment in the online discussion forum.
} 
resolved by deals specifying haircuts and maturity extensions, (iii) identifies key features of international markets important for generating maturity extensions, and (iv) shows how dynamic discrete choice methods can be applied to debt maturity and default problems.

Our first main contribution is to provide new empirical evidence on debt maturity extensions associated to restructurings. The most comprehensive and detailed dataset of sovereign debt restructurings is provided by Cruces and Trebesch (2013, 88 ), who conclude that "maturity extensions are a crucial component of overall debt relief" but do not directly show information on maturity extensions from restructurings. We extend their dataset by incorporating maturity extensions. Our results show that sovereign debt restructurings very often involve maturity extensions. We recover this variable from alternative measures of haircuts. In a large sample of distressed debt restructurings, we find that maturity was extended in the vast majority of the episodes, and the average extension was 3.4 years. We also show that maturity extensions were longer for defaulting economies in which output recovered more by the time of the restructuring.

Second, we provide insights about sovereign debt restructurings using a new quantitative model. Our setup is able to capture key features of debt restructurings while retaining the observed business cycle dynamics of sovereign debt and yield spreads. In our framework, the borrowing government selects the size and the maturity of its debt portfolio, where the decisions on whether to default and which debt maturity portfolio to select are affected by the current level of debt and its maturity, the country's income, and the expected terms of the restructuring. Sovereign debt is restructured in the context of a default. In a restructuring, lenders receive a new debt instrument that may differ from the original liabilities due to a combination of changes in the face value of the debt and a different repayment period. The size of the debt haircut and maturity extension from the restructuring are determined as the equilibrium result of a debt negotiation process where the lenders and the borrowing country make alternating offers. The model replicates two fundamental dimensions of sovereign debt restructurings, namely the size of the debt haircut and the maturity extension. The model also captures the dispersion in haircuts and maturity extensions explained empirically by differences in country characteristics at the time of restructuring: (i) countries that enter debt restructurings with larger debt burdens tend to experience larger debt haircuts, and (ii) borrowers with higher income at the time of restructuring experience a longer maturity extension of the restructured debt. The theoretical literature on restructurings and maturity extensions is scarce. A recent exception is the work of Aguiar et al. (2019) — henceforth, AAHW—which shows that an efficient restructuring reduces the maturity of the government debt portfolio. From this perspective, our empirical findings appear puzzling. The main mechanism in AAHW is that maturity extensions provide perverse incentives for fiscal policy going forward. Our quantitative model contains this same driving force, but we also consider other key features present during debt restructurings that may influence maturity extensions.

A third contribution of our paper is to evaluate the extent to which the AAHW and the novel restructuring features in our quantitative model capture the maturity extensions observed in the data. While long maturity debt is never chosen in the 
framework developed by AAHW, there are three drivers of maturity extensions in our framework. First, consistent with the data, income in the model recovers between the time of default and the debt restructuring. Defaults tend to occur when output is relatively low, and debt negotiation settlements generally happen once economic activity has improved and the risk of default of the new debt issued at settlement is lower. As debt maturity is procyclical, the output recovery between default and settlement implies that the chosen maturity of the new debt at settlement will be longer than the maturity at the time of default. Second, we include a period of financial markets exclusion after the debt restructuring. Empirically, this period may result from "stigma" associated with default and restructurings or from conditionalities often included in the restructuring arrangements. ${ }^{11}$ This exclusion period generates maturity extensions by reducing the perverse incentives of issuing long-term debt at the time of restructuring (i.e., debt dilution). Third, we consider the restructuring cost for lenders that arises from a haircut in the book value of the debt. This cost captures regulatory considerations that have historically affected financial institutions' decisions regarding sovereign debt holdings. ${ }^{2}$ Our quantitative analysis shows how these additional forces allow our model to match the data on maturity extensions, thus reconciling the theory with the data.

Our study also offers an important methodological contribution. We provide a new method to solve sovereign default models with endogenous maturity. It is quite challenging for quantitative studies to solve for the optimal default, debt, and maturity choices, and for the equilibrium prices of different bond types. Using methods from dynamic discrete choice, we introduce idiosyncratic shocks affecting the borrower's default and debt portfolio decisions. Under standard assumptions on the distribution of these shocks, we characterize the choice probabilities and use them to deliver a smooth equilibrium bond-price equation. Our proposed method can be conveniently applied to other quantitative debt models. ${ }^{3}$

Related Literature.-Our analysis builds upon several different strands of the literature on sovereign debt default, maturity, and restructuring. Following the seminal work on international sovereign debt by Eaton and Gersovitz (1981), a large portion of the literature on quantitative models of sovereign debt default has used only one-period debt (Arellano 2008, Aguiar and Gopinath 2006, among others). The next generation of models that include long debt duration, such as Hatchondo and Martinez (2009) and Chatterjee and Eyigungor (2012), features exogenous maturity. In contrast, our quantitative model features endogenous sovereign debt maturity and repayment under debt dilution. The work of Arellano and Ramanarayanan (2012) allows for the choice of long-term debt by having a short bond and a consol. We model debt maturity as the choice of a discrete number of periods following

\footnotetext{
${ }^{1}$ Richmond and Dias (2009) and Cruces and Trebesch (2013) document the existence of this exclusion period. IMF (2014) mentions that IMF conditionality is often part of restructurings. More on this is discussed in Section ID.

${ }^{2}$ Evidence of this is presented by Sachs (1986) for the Latin American debt crisis and Zettelmeyer, Trebesch, and Gulati (2013) for the most recent Greek crisis. More on this is discussed in Section ID.

${ }^{3}$ See, for instance, Mihalache and Wiczer (2018) for a recent application of our approach to other questions in the sovereign default and maturity literature.
} 
Sánchez, Sapriza, and Yurdagul (2018), which is computationally convenient for the application of dynamic discrete choice methods.

Our work is also related to recent models on sovereign default and restructurings. The first model that combined the Eaton and Gersovitz (1981) framework with debt renegotiation was the study by Yue (2010) that considered a Nash bargaining approach. Also closely related to our analysis is the recent work by Mihalache (2017) that explores sovereign debt restructurings and maturity extensions appealing to political economy considerations. These works have an exogenous length of negotiation, instead of a restructuring mechanism like Benjamin and Wright (2013) that delivers endogenous delays as in our model. Delays are studied in detail in a stylized framework by Benjamin and Wright (2018), where the authors explain several ways of obtaining delays in sovereign debt renegotiations. In particular, they show that when the government cannot issue state-contingent securities, delays arise because the risk of default on the non-state-contingent securities serves to reduce the value of an immediate settlement. This mechanism is at work in our setup, and it is important in generating maturity extensions since income recovers between the time of default and restructuring. The role of income and cyclical conditions on haircuts and recovery rates has also been studied by Sunder-Plassmann (2018).

Other related work in the literature includes Asonuma and Trebesch (2016) and Asonuma and Joo (2017), which study different aspects of sovereign debt restructurings in the context of one-period bond models. Recent complementary work by Arellano, Mateos-Planas, and Ríos-Rull (2019) focuses on the role of partial defaults on restructuring dynamics. ${ }^{4}$

Our method to solve the numerical challenges presented by this setup follows a similar intuition as Chatterjee and Eyigungor (2012), who introduce a random i.i.d. shock to income to smooth the borrower's default decision. ${ }^{5}$ However, there are important differences between our proposed method and theirs. Crucially, in their approach, this shock adds one more state variable to the problem of the borrower. Thus, a direct extension of that approach to our context would require a very large set of these shocks, greatly increasing the number of state variables in the model and, thus, rendering the problem intractable. We employ the Generalized Extreme Value distribution (McFadden 1978), which has long been used in other areas of economics and provides a tractable way to characterize agents' decision rules. Our approach delivers smooth decision rules for default, maturity, and debt choices without increasing the number of state variables in the problem. ${ }^{6}$

\footnotetext{
${ }^{4}$ Our work is also related to other types of default resolution or prevention mechanisms. Bianchi (2016) and Roch and Uhlig (2016) study the desirability of bailouts and show that in some cases, bailouts may induce additional borrowing that offsets their potential benefits. Related work finds similar results analyzing the introduction of contingent convertible bonds or voluntary debt exchanges (see, for instance, Hatchondo, Martinez, and Sosa-Padilla 2014).

${ }^{5}$ See also Pouzo and Presno (2012).

${ }^{6}$ In a recent paper, Chatterjee et al. (2016) introduce extreme value shocks to a model of consumer borrowing and default. The reason they employ these shocks is not due to the complexity of the borrower's problem, as they have one-period debt with zero recovery in case of default, but as a way to compute the Bayes-Nash equilibrium in a model of private information with a signal extraction problem. In their model, these shocks are a force that ensures that all possible actions by consumers have a positive probability of occurrence. In this way, there is no need to deal with off-equilibrium-path beliefs as is usual in equilibrium models with private information.
} 
The remainder of our paper is organized as follows. Section I describes the construction of a new dataset of maturity extensions in debt restructurings and discusses the empirical regularities that help understand the maturity extensions obtained from the data. Sections II to V present the model environment, the driving mechanisms, and the equilibrium. In particular, Section II describes the economic setup, Section III discusses the default and repayment decisions faced by the sovereign, Section IV offers a detailed analysis of the debt restructuring process, and Section V presents the equilibrium. The calibration and statistical fit are explained in Section VI, and a quantitative assessment of the maturity extensions generated by the model is performed in Section VII. Section VIII discusses the discrete choice with extreme value shocks methodology used to solve the model. Finally, the concluding remarks are provided in Section IX.

\section{Empirical Evidence}

There are several papers documenting sovereign debt restructurings (Cruces and Trebesch 2013, Sturzenegger and Zettelmeyer 2005). Many of these studies have focused on developing alternative measures of sovereign debt reduction after a restructuring episode, i.e., a debt haircut, and have produced many descriptive statistics associated to haircut measures. However, these studies have provided little statistical analysis on the change in maturity associated with restructuring episodes, a key aspect of haircuts. In this section, as a first step, we propose and implement a method to recover maturity extensions from a dataset by Cruces and Trebesch (2013) for a large number of distressed sovereign debt restructuring events between 1970 and 2013. In a second step, we include our maturity extension measures and a number of macroeconomic variables in the dataset by Cruces and Trebesch (2013) and use our expanded annual dataset to show how haircuts and maturity extensions vary with countries' borrowing and business cycle conditions. Finally, we document three key empirical stylized facts that help explain the presence of maturity extensions in restructurings. The empirical findings in this section guide our choices in the quantitative model of sovereign debt restructuring presented later in the paper.

\section{A. Constructing a New Dataset of Maturity Extensions}

The growing literature on sovereign debt defaults has compiled and analyzed data for more than 150 distressed sovereign debt restructurings, but until now, there was no statistical description of the maturity extensions involved in these debt events. We use the comprehensive sovereign debt restructurings data of Cruces and Trebesch (2013) to derive a dataset of maturity extensions. To do so, we consider three measures of debt haircuts (Face value (HFV), Market value (HMV), and Sturzenegger-Zettelmeyer (HSZ)), the discount rates used to value future cash flows, and we proceed in three main steps summarized below (see online Appendix for additional details).

In the first step, we derive the maturity of the debt after restructuring (new debt). This requires expressing the ratio of the complements of HMV and HFV in terms of the ratio of the face value and present value of new debt. We express the ratio 
Table 1 -Descriptive Statistics, Baseline Sample

\begin{tabular}{lcccccr}
\hline \hline Variable & Mean & $\mathrm{p} 50$ & $\mathrm{p} 25$ & $\mathrm{p} 75$ & $\mathrm{SD}$ & Observations \\
\hline Market value haircut, $H_{M}$ & 0.456 & 0.426 & 0.228 & 0.769 & 0.268 & 162 \\
SZ haircut, $H_{S Z}$ & 0.385 & 0.305 & 0.184 & 0.646 & 0.244 & 162 \\
Face value haircut, $H_{F V}$ & 0.209 & 0.091 & 0 & 0.535 & 0.238 & 162 \\
Discount factor & 0.141 & 0.142 & 0.123 & 0.153 & 0.032 & 162 \\
New debt maturity, $N_{\text {new }}$ & 7.267 & 5.907 & 2.986 & 9.979 & 6.63 & 161 \\
Old debt maturity, $N_{\text {old }}$ & 4.008 & 4.568 & 0.969 & 7.772 & 3.084 & 140 \\
Maturity extensions & 3.365 & 2.207 & 0.329 & 2.837 & 6.408 & 140 \\
\hline
\end{tabular}

Note: We weight by the total amount of debt restructured, unless explicitly noted. Our baseline sample excludes donor-supported restructurings.

Source: Authors' calculations based on the Cruces and Trebesch (2013) dataset on debt restructuring haircuts.

between the face value and present value of new debt in terms of the maturity of new debt and the underlying discount rate used to value future cash flows under alternative payment structures over time for the new debt. We considered uniform and decaying payment structures with alternative rates of decay. The empirical results discussed in this section correspond to a uniform payment structure, but results are robust to alternative specifications. As the ratio and the discount rates are known, the maturity of new debt is the only unknown in a single equation and can be easily retrieved. Second, we recover the maturity of the old debt (debt defaulted upon) at the time of restructuring in a similar way but instead using the formulas for MV and SZ to derive the ratio of the face and present value of the old debt and adjusting for the observable duration of default, i.e., the length of the period between default and restructuring. The third and final step involves the estimation of the maturity extension, which is obtained as the difference between the maturity of the new debt calculated in the first step and the maturity of the old debt at the time of restructuring calculated in the second step. ${ }^{7}$

\section{B. Resulting Maturity Extensions}

This section presents the data to which we applied the methodology described in the previous section as well as the results. Table 1 shows that the mean SZ haircut is 38.5 percent and the maturity extension is on average 3.4 years. The table also shows that there is significant dispersion in all the statistics used. For instance, the market value haircuts vary between 23 percent and 77 percent for the percentiles 25 and 75 , respectively.

To evaluate our results, we now compare the findings of our method with more detailed information about maturity extensions available for Argentina's debt restructuring in 2005. With our method, we recover an estimate of 27.1 years for the maturity extension in the global restructuring. Using information for about 66 securities (bond by bond) provided by Sturzenegger and Zettelmeyer (2005), we find that the maturity of the old debt was 9 years. For the new bonds, only a few options were offered to creditors. Obtaining maturity is relatively straightforward because

\footnotetext{
${ }^{7}$ See online Appendix for more details.
} 
Table 2-Maturity Extensions, Alternative Samples

\begin{tabular}{lcccccc}
\hline \hline Variable & Mean & $\mathrm{p} 50$ & $\mathrm{p} 25$ & $\mathrm{p} 75$ & $\mathrm{SD}$ & Observations \\
\hline Baseline sample & 3.365 & 2.207 & 0.329 & 2.837 & 6.408 & 140 \\
High-quality data & 3.772 & 2.207 & 0.329 & 2.837 & 6.869 & 99 \\
Including "donors" & 3.368 & 2.207 & 0.329 & 2.837 & 6.407 & 144 \\
Nonweighted & 2.662 & 1.731 & 0.233 & 3.889 & 4.069 & 140 \\
Europe & 2.636 & 2.207 & 2.207 & 2.207 & 1.763 & 28 \\
Africa & 2.77 & 2.645 & 1.123 & 2.645 & 2.21 & 35 \\
Latin America & 4.079 & 0.904 & 0 & 3.122 & 8.531 & 66 \\
\hline
\end{tabular}

Notes: Extensions expressed in years. We weight by the total amount of debt restructured, unless explicitly noted. Our baseline sample excludes donor-supported restructurings.

Source: Authors' calculations based on Cruces and Trebesch (2013) dataset on debt restructuring haircuts.

the dollar-denominated bonds have a maturity of either 30 or 35 years, so we take the total maturity of the new bonds to be 35 years. This implies that the total maturity extension obtained using detailed information is 26 years, remarkably close to those obtained with our method, 27.1 years.

Similarly, Mihalache (2017) estimates that in Greece's restructuring of 2012, the risk-free Macaulay duration was lengthened by 1.4 years, from 6.4 to 7.8 years. Our method recovers a maturity extension of 2.2 years for this episode.

For the main descriptive statistics described in Table 1, we restrict our attention to cases not involving debt relief to highly indebted low-income economies, and we weight each restructuring episode by the amount of restructured debt. ${ }^{8}$ In Table 2, we show how maturity extensions vary when we consider alternative subsamples and weights.

The main conclusion to draw from this table is that maturity extensions remain significant for different samples, time periods, weightings, and regions. In most cases, maturity extensions are larger than three years, and they have been larger in the Latin American debt restructurings.

To gain more insights about maturity extension, it is useful to present the results together with the SZ haircut that resulted from that restructuring. Figure 1 plots haircuts and maturity extensions, showing the two are positively correlated. In that plot, it is possible to identify different types of debt restructurings based on the varying degrees of debt maturity extensions and SZ haircuts associated to payment reschedulings and reductions in the face value of principal or coupon payments.

Distressed debt exchange events, such as the one in Pakistan in 1999 or Uruguay in 2003, involved the rescheduling of debt payments and little or no face value reductions either in the principal or in coupon payments. The SZ haircuts and creditor losses tend to be low in these cases, referred to as "reprofilings." They were most frequent in the 1980s and have regained significant attention in international financial markets in recent years. Debt crises like that of Ukraine in 2000 were resolved with somewhat larger maturity extensions and some debt value reduction in coupons or principal that implied SZ haircuts generally below 30 percent. These so-called "soft restructurings" are also quite prevalent in the data. Debt resolution operations

\footnotetext{
${ }^{8}$ Donor-supported restructurings are those cofinanced by the World Bank's Debt Reduction Facility. See Cruces and Trebesch (2013).
} 


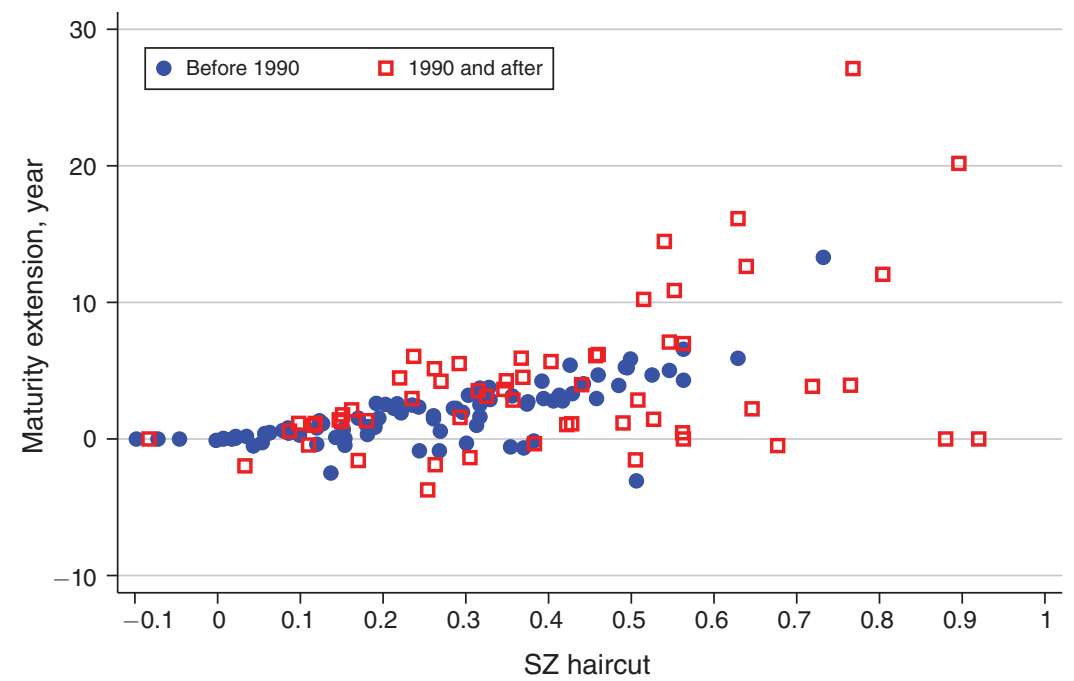

Figure 1. Haircuts ANd Maturity Extensions

Source: Authors' calculations based on the Cruces and Trebesch (2013) dataset of debt restructuring haircuts

like those for Ecuador in 2000 or the Brady restructurings for countries like Mexico or Philippines, among others, are characterized by longer maturity extensions and larger reductions in coupons and principal that when combined, amount to moderate but permanent capital losses for creditors, with SZ haircuts between 30 and 50 percent. The "hard restructurings" implemented in the largest and most severe debt crises, such as Argentina in 2005, were generally associated with 20- to 30-year maturity extensions and deep face value reductions in both principal and coupons, which translated into (SZ) haircuts ranging from 50 to about 80 percent.

\section{Accounting for the Variation in Haircuts}

We first show results from regressions of haircuts with some key macro variables. In a second stage, we analyze whether our quantitative model of sovereign debt restructuring displays similar relationships with these variables.

Table 3 presents regressions of $H_{S Z}$ haircuts for the "full" sample of more than 150 default episodes. 9 For robustness, we also present results for a "restricted" set of restructurings that are not donor-supported.

The first row in Table 3 indicates that countries that enter default with a larger debt burden exhibit larger haircuts. The effect is statistically significant for both the restricted and the full sample. The second row shows the effect of income on haircuts. To keep the regression comparable with the data, we detrended $\log$ (GDP)

\footnotetext{
${ }^{9}$ While there are 187 restructuring episodes in Cruces and Trebesch (2013), we complement their dataset with additional information on GDP, population, and year of default. For some countries and time periods, we do not have this information, and thus a few observations are dropped. The regressions shown in the table include dummy variables "1990s" and "2000s" that take a value of one if the restructuring was in that decade and zero otherwise. The variable "2000s" also includes two episodes available after the year 2010. All regressions also have a constant and dummy variables for the continent of the country and GDP per capita.
} 
TABLE 3-Determinants OF SZ HaIRCUTS

\begin{tabular}{lcc}
\hline \hline $\log ($ SZ haircut $)$ & Restricted & Full sample \\
\hline $\log ($ debt $/$ GDP $)$ & 0.526 & 0.506 \\
GDP cycle & $(0.152)$ & $(0.124)$ \\
& -1.772 & -0.595 \\
Observations & $(3.308)$ & $(2.892)$ \\
$R^{2}$ & 124 & 144 \\
\end{tabular}

Notes: Robust standard errors are shown in parentheses. The restricted sample does not include restructurings that Cruces and Trebesch (2013) classify as "donor."

using the Hodrick-Prescott (HP) filter and included the resulting GDP cycle as the explanatory variable. The effect of the business cycle on haircuts is negative but not statistically different from zero for either sample.

\section{Reasons for Maturity Extensions}

We use Cruces and Trebesch (2013) data on sovereign debt restructurings and look into the empirical literature on sovereign defaults and restructurings to discuss three empirical regularities that are relevant to understanding some of the main mechanisms underlying sovereign default resolutions. The three key stylized facts can be summarized as follows: First, the borrower's income generally recovers between default and restructuring. Second, the borrowing country tends to experience constraints to credit market access following a sovereign debt restructuring. Third, banking regulations have historically favored restructurings without book value haircuts. In the remainder of the section, we explore each of these empirical facts in more detail and explain why they matter for maturity extensions.

Income Recovers between Default and Restructuring.--Sovereign borrowers generally default when they are experiencing relatively weak output and tend to conclude their debt restructurings when economic conditions have improved. Intuitively, a stronger economy is less likely to default, and hence the debt issued at settlement will have a higher market value. Table 4 shows the cumulative percentage change in output over the length of default-i.e., the duration of default from the time the country enters default to the time of the exit settlement-for different default lengths expressed in years. The third and fourth columns present the change in output measured as the deviations of output from its HP trend. As shown, the mean and median output deviations from trend increase while the country is in default, and that result is robust to different default durations, shown at one-year increments. The dispersion in the income recovery (not shown) suggests nevertheless that there is substantial variation across country events and that this variation occurs for all default durations. The last two columns of the table provide similar results, considering output per capita instead of output deviations from trends. These findings are consistent with the empirical facts discussed in Benjamin and Wright (2013).

The output recovery is related to important features of the debt at the time the borrower concludes the restructuring process. Benjamin and Wright (2013) point out the 
Table 4-Economic Recovery from Default until Restructuring, By Length (Years) of the Default Episode

\begin{tabular}{|c|c|c|c|c|c|}
\hline & \multirow[b]{2}{*}{ Cases } & \multicolumn{2}{|c|}{ GDP cycle } & \multicolumn{2}{|c|}{ GDP per capita } \\
\hline & & Mean & Median & Mean & Median \\
\hline All & 148 & $2.3 \%$ & $0.0 \%$ & $2.7 \%$ & $0.0 \%$ \\
\hline Length $>0$ & 124 & $2.8 \%$ & $0.4 \%$ & $3.2 \%$ & $0.3 \%$ \\
\hline Length $>1$ & 100 & $3.8 \%$ & $0.7 \%$ & $4.3 \%$ & $1.5 \%$ \\
\hline Length $>2$ & 87 & $4.1 \%$ & $0.6 \%$ & $4.6 \%$ & $1.0 \%$ \\
\hline Length $>3$ & 68 & $5.4 \%$ & $1.7 \%$ & $6.3 \%$ & $2.3 \%$ \\
\hline Length $>4$ & 47 & $6.7 \%$ & $4.3 \%$ & $6.7 \%$ & $3.5 \%$ \\
\hline
\end{tabular}

Source: Authors' calculations using data from the Cruces and Trebesch (2013) dataset, the Penn World Table (Feenstra, Inklaar, and Timmer 2015), and IMF (International Monetary Fund 2019)

relevance of the output recovery to understand the borrower's level of debt-to-GDP. We complement their analysis by focusing on the implications for sovereign debt maturity. Specifically, to the extent that sovereign debt maturity is procyclical (see, for instance, Sánchez, Sapriza, and Yurdagul 2018), the output recovery between the period of default and restructuring implies that the maturity of the new debt chosen upon settlement would be larger than the maturity of debt at the time of default. Figure 2 presents the observations for income recovery grouped in quintiles and the corresponding maturity extensions from our sample. The plot shows the positive empirical correlation between the income recovery (red bars) and the extension of maturity (blue bars).

Protracted Credit Market Exclusion after Debt Restructuring.-In the first few years following a sovereign debt restructuring, countries tend to experience difficulties accessing credit markets. Cruces and Trebesch's (2013) empirical analysis estimates the probability that a country remains excluded after restructuring as a function of the time since the restructuring. The results are shown by the gray line in Figure 3. The red line in this figure is the exclusion probability with a constant reentry probability of 30 percent, which we use later in the calibration of our quantitative model. The figure shows that it usually takes a long time to get back to credit markets after a restructuring event. Our constant hazard function appears to fit the data well for the first five years post-restructuring and then gives a conservative estimate of credit market exclusion.

Richmond and Dias (2009) also report the existence of an exclusion period after sovereign debt restructurings, interpreting this to mean that credit markets "punish" countries after a restructuring. ${ }^{10}$ The exclusion after a restructuring also captures the existence of conditionalities that are often part of negotiation settlements and that provide safeguards to the lenders that the value of the bonds issued in the restructuring will be sustained. 11

\footnotetext{
${ }^{10}$ While this "punishment" is not endogenously modeled here, it could be endogenously generated if lenders learned about the type of the country (e.g., patient or impatient) in a default or restructuring episode. Amador and Phelan (2018) provide a theory along these lines.

${ }^{11}$ Of the 17 arrangements reviewed in an IMF report from 1998 to 2014 (IMF 2014), 11 included conditionalities related to the restructuring. The work by AAHW mentions that many restructurings involving official
} 


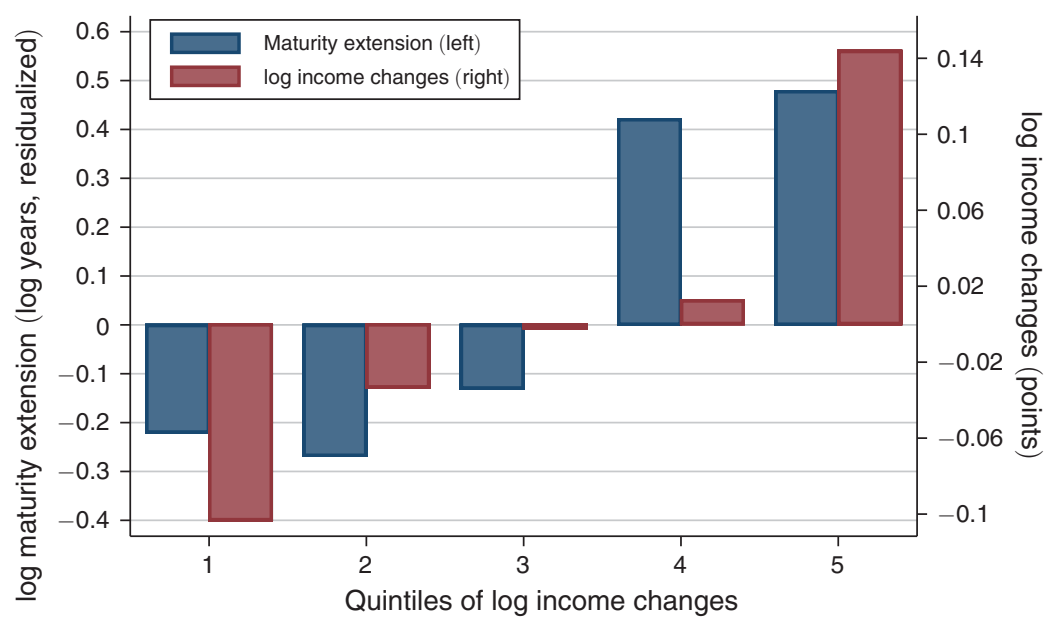

Figure 2. Income Recovery and Maturity Extensions

Notes: The log of maturity extensions is conditional on the log of debt to GDP. The five groups correspond to quintiles of recovery in the business cycle between the time of default and restructuring.

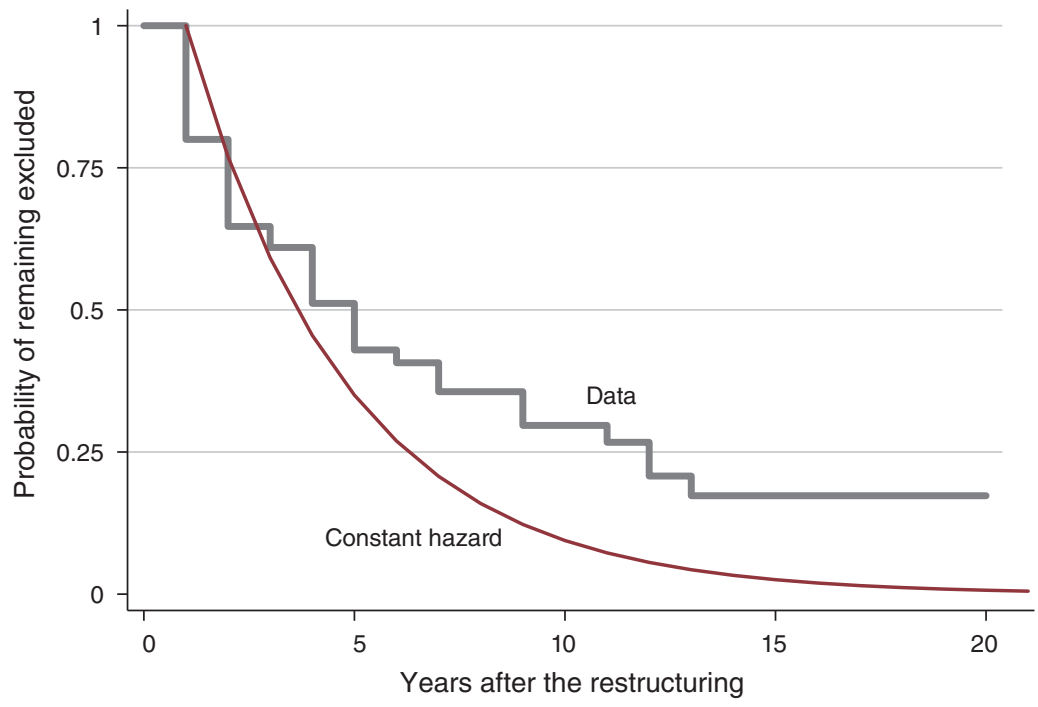

Figure 3. Protracted Exclusion of Credit Markets after Restructuring

Notes: The gray line denotes the Kaplan-Meier survival estimate, which we compute using data from Cruces and Trebesch (2013). It represents the unconditional joint probability a country remains excluded from capital markets until that many years after the restructuring. The constant hazard line shows the theoretical survival probability using an exponential model and a constant hazard of $\log (1.3)$.

There are two reasons this empirical regularity matters for the debt maturity preferences of the borrower and lender when exiting a restructuring and thus for the pricing of the new debt. First, because countries know that most likely they

agencies, such as the IMF or EU, impose conditionalities on the debtor to deal with the perverse incentive of countries to issue new debt in the future. 
will not have access to credit markets in the short run, they hedge against this risk by spreading debt payments over time, thus borrowing long term. Second, lenders know that debt will most likely not be diluted in the short run, so the prices of long-term debt are more favorable relative to a case in which countries can access financial markets immediately after restructuring and issue new debt.

\section{Banking Regulations Favor Restructurings without Book Value Haircuts.-} Sturzenegger and Zettelmeyer (2006) point out a key way in which the role of the official sector in sovereign debt disputes changed after World War II, which was that creditor governments began influencing debt restructuring agreements through channels that did not exist or that were less common prior to the war, including regulatory pressure or forbearance with respect to creditor banks.

There is ample evidence concerning the role of banking regulations during the debt events of the 1970s and 1980s. During debt negotiations in the late 1970s, banks tried to rely entirely on refinancing, motivated in part by regulatory incentives. As Rieffel (2003) documents, by maintaining debt service financed by new lending, banks could avoid classifying loans as impaired, which would have forced them to allocate income to provision against expected losses. There is a long literature describing the role of bank regulation in the debt negotiations of the 1980s. Sachs (1986) explains that creditor government policies supported the commercial banks through their decisions on bank supervision, mainly as the US banking regulators allowed the commercial banks to hold almost all of their sovereign debt on their books at face value.

During the Latin American debt crisis, sovereign debt was mostly loans by US banks. The study by Guttentag and Herring $(1989,14)$ explains:

Book values may also matter to banks because they matter to regulators. Capital requirements, for example, are defined in terms of book values. If a bank's capital falls below the regulatory minimum, the bank may be subject to closer surveillance than usual, and it may lose its freedom of action on mergers and acquisitions, dividend payments, branch expansion, advertising expenditures, and even loan policy. Indeed, a serious shortfall in book capital that is not remedied quickly can be cause for merging the bank or replacing the management.

If creditors and regulators do react to changes in book values, the use of book values in the bank's decision-making is not inconsistent with the goal of maximizing the wealth of its shareholders.

Consequently, Guttentag and Herring (1989) provides a model of banking in which the bank perceives a cost to reducing the stated value of claims on the borrower that is proportional to the book value of those claims. Later in our quantitative model, we add the same type of costs, specified as $\kappa \times \max \{x, 0\}$, where $x$ is the reduction in the face value of debt and $\kappa$ is a parameter capturing the cost of raising bank equity. This assumption implies that lenders and borrowers will place greater emphasis on negotiating agreements that maintain the book value of the claims. To avoid regulatory pressures due to capital losses, banks have the option to raise capital to offset the book value losses. It is hard to estimate precisely the cost of a capital shortfall due to a decline in the book value of assets, but the cost of raising equity by 
banks provides an upper bound. Why? Because that is the cost in the case in which all debt is held by banks and the capital requirement constraints are binding for all banks. This upper bound is estimated by many papers, and the results for US banks are summarized in Lopez (2001), who shows that on average, it is about 12 percent. Thus, in the case of the Latin American debt crisis in the 1980s, where a very large portion of creditors were US banks, something close to 12 percent is likely reasonable. For other episodes, it may be much lower. The share of sovereign debt held by banks is hard to estimate and has varied over time and across countries, but it has generally been quite economically significant. Ffrench-Davis and Devlin (1993) estimate that in the early 1980s, about 80 percent of Latin American external debt (mostly public debt) was held by banks, on average. For developing countries as a whole, they document that the share of bank holdings was about 60 percent. Brutti and Sauré (2013) report a lower average share for 15 advanced economies in the late 2000 s, with an average of about 35 percent. This includes a low value for the United States (6 percent) and values above 50 percent for some European economies (see their table A2). Hence, in the calibration of our quantitative model, we adopt a conservative benchmark by considering that half of the debt is held by banks and that the capital requirement constraint is binding for half of them. In this case, the value of that extra cost (parameter $\kappa$ ) is 3 percent. ${ }^{12}$

Recently, direct bank loans to countries have become rare, but banks hold sovereign debt, and regulatory considerations remain a crucial factor influencing negotiations. Das, Papaioannou, and Trebesch $(2012,83)$ highlighted this point by arguing that in the early 1980s, low haircuts in debt restructurings were observed because "Western banks faced considerable solvency risk due to their exposure to developing country sovereign debt." They also argued that "similar concerns apply today in Europe, as European banks hold significant amounts of sovereign debt of Euro-periphery countries on their books. Therefore, a restructuring with large haircuts may become a source of systemic instability in the financial sector if appropriate remedial measures are not adopted." Similarly, in explaining the Greek restructuring, the study by Zettelmeyer, Trebesch, and Gulati $(2013,3)$ states that "most Greek bonds were held by banks and other institutional investors which were susceptible to pressure by their regulators and governments."

The study by Blundell-Wignall and Slovik (2010) explains the details of the regulation of European banks and stress testing before the Greek restructuring. Banks can have bonds in "the trading books" or in "banking books." In the trading books, they are marked to market, so book value haircuts or face value haircuts are the same. But on the banking books, it is assumed they will be held to maturity, so they are priced at book value. They show that on average, 83 percent of the sovereign bonds are held on banking books. Thus, this mechanism is also important for the restructuring of bonds, as long as a significant share of them is held by banks. In the case of Greece, it was clear that Greek banks would have gone bankrupt, and losses would have threatened the solvency of other European banks, particularly in Germany and France.

\footnotetext{
${ }^{12}$ In Section VIIC, we show how results are affected by changing the value of this parameter.
} 


\section{Environment}

We consider a small open economy model with a stochastic endowment and a benevolent government à la Eaton and Gersovitz (1981). The government participates in international credit markets facing risk-neutral lenders and lacks commitment to repay its obligations. Therefore, given an outstanding amount of assets $b$ (debt if $b<0$ ), the sovereign chooses either to default or to keep its good credit status by paying its obligations.

A default brings immediate financial autarky and a direct output loss to the defaulting country. After the initial default decision, the country has the opportunity to return to international debt markets but only after restructuring its debt. The restructuring of the debt may entail a haircut and a different maturity from the original defaulted portfolio.

When in good credit status, the country may face a "debt rollover" shock, $a$, where $a=1$ if the country is facing a disruption in its access to financial markets and is hence impeded from rolling over or changing its debt portfolio, and $a=0$ otherwise. When the country experiences this "sudden stop" event, world financial markets cease to lend to the economy, so the country may only choose between repaying and repudiating its obligations. ${ }^{13}$

If the country decides not to default, it selects the maturity of the new portfolio, $m^{\prime}$, and the debt level, $b^{\prime}$. The optimal choices of maturity and asset levels are influenced by the current level of income, the current level of debt and its maturity, and the debt rollover shock. There is also a cost of adjusting the portfolio, discussed in the model calibration section. 14

The conditions of the debt restructuring are endogenously determined via an alternating-offers mechanism that resembles that of Benjamin and Wright (2013). That is, each period in default, either the lender or the borrower has a chance to make a restructuring offer to the other party. If the lender is making the offer, the lender selects a market value of restructured debt, and the borrower decides whether to accept the offer, and, if so, the yearly payments $b^{R}$ and maturity $m^{R}$ to deliver the asked market value. In this case, the restructuring proposal takes into account the incentives of the borrower to accept the restructuring deal or not. If the borrower is the one proposing a deal, it will choose the offer that makes the lender indifferent on whether to accept or not. However, if the value of such a deal is sufficiently large, the borrower may choose not to make a restructuring offer at all and continue in default.

To make the problem tractable, we make a few assumptions about the support of the assets and introduce additive preference shocks to choices. In Section VIII, we show how additional assumptions on the distribution of these shocks make the

\footnotetext{
${ }^{13}$ We introduce sudden stop shocks in our model to get a sufficiently high level of debt maturity in normal times. It is well known that for borrowers, long-term debt is more costly than short-term debt due to debt dilution. However, borrowers value long-term debt as a way to hedge against rollover crises or sudden stops (see Sánchez, Sapriza, and Yurdagul 2018 for a discussion). In our quantitative exercises and for our preferred calibration, only 17.5 percent of all default episodes occur jointly with a sudden stop. The online Appendix shows that our results about debt restructurings and maturity extensions are robust to removing these sudden stops.

${ }^{14}$ We explain the role and properties of this adjustment cost in the calibration section, and we show it in Appendix A, where we present all the model equations.
} 
problem more tractable to solve it computationally. First, we assume that the maturity of the new asset portfolio can be a natural number $m^{\prime} \in\{1,2, \ldots, \mathcal{M}\}$. In addition, we assume that assets can only take values in a discrete support. This discrete grid has a total of $\mathcal{N}$ points. ${ }^{15}$ With this pair of assumptions, we can characterize the problem of the government as choosing either the optimal debt and maturity combination or to default. This decision boils down to choosing one out of many possible alternatives. When writing down the problem, it is convenient to define vectors $b$ and $m$, where $\left(b_{j}, m_{j}\right)$ are the $j$ th elements of each vector, respectively. These vectors have $\mathcal{J}=\mathcal{M} \times \mathcal{N}$ elements and the following structure:

$$
\begin{aligned}
& b=[\underbrace{b_{1}, b_{2}, \ldots, b_{\mathcal{N}}}_{\text {grid for } b}, \underbrace{b_{1}, b_{2}, \ldots, b_{\mathcal{N}}}_{\text {grid for } b}, \ldots, \underbrace{b_{1}, b_{2}, \ldots, b_{\mathcal{N}}}_{\text {grid for } b}]^{T}, \\
& m=[\underbrace{m_{1}, m_{1}, \ldots, m_{1}}_{\text {repeated } \mathcal{N} \text { times }}, \underbrace{m_{2}, m_{2}, \ldots, m_{2}}_{\text {repeated } \mathcal{N} \text { times }}, \ldots \underbrace{m_{\mathcal{M}}, m_{\mathcal{M}}, \ldots, m_{\mathcal{M}}}_{\text {repeated } \mathcal{N} \text { times }}]^{T},
\end{aligned}
$$

where the operator $T$ represents the transpose.

Second, we assume there is a random vector $\epsilon$ of size $\mathcal{J}+1$, where the size corresponds to the number of all possible combinations of $b$ and $m$, captured by $\mathcal{J}=\mathcal{M} \times \mathcal{N}$, and one additional element that captures the choice of default. We label the elements of the random vector $\epsilon$ as $\epsilon_{j}$ and the one associated with the choice of default as $\epsilon_{\mathcal{J}+1}$. As mentioned, the introduction of these $\mathcal{J}+1$ shocks is useful to solve our model numerically using the tools of dynamic discrete choice. ${ }^{16}$

We assume $\epsilon$ is drawn from a multivariate distribution with joint cumulative density function $F(\boldsymbol{\epsilon})=F\left(\epsilon_{1}, \epsilon_{2}, \ldots, \epsilon_{\mathcal{J}+1}\right)$ and joint density function $f(\boldsymbol{\epsilon})=f\left(\epsilon_{1}, \epsilon_{2}, \ldots, \epsilon_{\mathcal{J}+1}\right)$. To simplify notation in what follows, we use the following operator to denote the expectation of any function $Z(\epsilon)$ with respect to all the elements of $\epsilon$ :

$$
E_{\epsilon} Z(\boldsymbol{\epsilon})=\int_{\epsilon_{1}} \int_{\epsilon_{2}} \cdots \int_{\epsilon_{\mathcal{J}+1}} Z\left(\epsilon_{1}, \epsilon_{2}, \ldots, \epsilon_{\mathcal{J}+1}\right) f\left(\epsilon_{1}, \epsilon_{2}, \ldots, \epsilon_{\mathcal{J}+1}\right) d \epsilon_{1} d \epsilon_{2} \cdots d \epsilon_{\mathcal{J}+1} .
$$

\section{Normal Times}

Under the economic setup described above, the country's choice when in good credit standing can be expressed as

$$
V^{G}\left(y, a, b_{i}, m_{i}, \boldsymbol{\epsilon}\right)=\max \left\{V^{D}\left(\min \left\{y, \pi^{D}\right\}, b_{i}, m_{i}, \epsilon_{\mathcal{J}+1}\right), V^{P}\left(y, a, b_{i}, m_{i}, \boldsymbol{\epsilon}\right)\right\},
$$

\footnotetext{
${ }^{15}$ The last assumption could be interpreted as units for debt or assets. For example, in practice, agents choose savings or debt in multiples of cents or dollars. What we have in mind, however, is a more sparse and bounded support for sovereign debt, such as millions of dollars or one-tenth of a percent of GDP. The assumption of a discrete and bounded support for debt is usual in the sovereign default literature (Chatterjee and Eyigungor 2012).

${ }^{16}$ See the discussion and details in Section VIII, where we also provide an economic interpretation for these shocks. As we show there, these shocks play a very modest role in the decisions of borrowers, with a slightly larger impact in determining the choice of maturity in those cases for which the country is almost indifferent among several alternatives.
} 
where $V^{D}$ and $V^{P}$ are the values if the country chooses to default and repay, respectively; the subindex $i$ represents the last period choice of $b$ and $m$; and $\min \left\{y, \pi^{D}\right\}$ represents the income of the country net of the punishment for entering in default. Note that countries with income $y$ above $\pi^{D}$ have an output loss equal to $y-\pi^{D}$, and countries at or below that threshold have no losses.

The policy function $D\left(y, a, b_{i}, m_{i}, \boldsymbol{\epsilon}\right)$ is one if default is preferred and zero otherwise.

In case of default, the problem is simply

$$
V^{D}\left(y, b_{i}, m_{i}, \epsilon_{\mathcal{J}+1}\right)=u(y)+\beta E_{y^{\prime} \mid y} E_{\epsilon^{\prime}} V^{R}\left(\min \left\{y^{\prime}, \pi^{R}\right\}, b_{i}, m_{i}, \epsilon^{\prime}\right)+\epsilon_{\mathcal{J}+1},
$$

where $\min \left\{y, \pi^{R}\right\}$ represents the income of the country net of the punishment for staying in default.

In case of repayment, the value depends on the rollover shock, $a$. In normal times (i.e., no debt rollover shock, $a=0$ ), the value is

$$
V^{P}\left(y, 0, b_{i}, m_{i}, \boldsymbol{\epsilon}\right)=\max _{j} u\left(c_{i j}(y)\right)+\beta E_{y^{\prime}, a^{\prime} \mid y, 0} E_{\epsilon^{\prime}} V^{G}\left(y^{\prime}, a^{\prime}, b_{j}, m_{j}, \epsilon^{\prime}\right)+\epsilon_{j}
$$

subject to

$$
c_{i j}(y)=y+b_{i}+q\left(y, 0, b_{j}, m_{j} ; m_{i}-1\right) b_{i}-q\left(y, 0, b_{j}, m_{j} ; m_{j}\right) b_{j}
$$

and

$$
j \in\{1,2, \ldots, \mathcal{J}\} .
$$

The expectation is about future income and rollover conditions. We assume that the transition probability from $a=0$ (access to bond market) to $a=1$ (no access to bond market) is $\omega^{N}$. The constraint implies that consumption is equal to income, $y$, net of debt payments, $b_{i}$, plus the net resources that are obtained from, or paid to, international markets, as captured by the next two summands. ${ }^{17}$ The first of these two summands depends on the market price of outstanding obligations, $q\left(y, 0, b_{j}, m_{j} ; m_{i}-1\right)$, which takes into account the current income, $y$; the debt rollover shock, $a=0$; and the obligations the country will have from the beginning of the next period, $\left(b_{j}, m_{j}\right)$. These four variables determine the risk of default. The market price also depends on $m-1$, which is the remaining number of years of payments of the outstanding debt after the current year's payment. The term $q\left(y, 0, b_{j}, m_{j} ; m_{i}-1\right)$ captures the price per unit of resources promised per year. It is multiplied by $b_{i}$ to reflect the market value of the total outstanding obligations at the beginning of the present period. With a negative value of $b$, the term represents the gross resources leaving the country. Similarly, the term $-q\left(y, 0, b_{j}, m_{j} ; m_{j}\right) b_{j}$ is the value of the outstanding debt at the end of the current period and, therefore, represents the gross resources

\footnotetext{
${ }^{17}$ We assume a flat profile of $-b_{i}$ yearly payments as in Sánchez, Sapriza, and Yurdagul (2018). We can easily have a decreasing profile of payments with an exogenous decaying rate to match some features of the data. However, the decreasing profile is independent of the maturity of the debt, which is well defined in our setup.
} 
obtained from international markets. The combination of both terms captures the net resources obtained from international markets.

The policy functions for the amount of assets and maturity choices are $B\left(y, a, b_{i}, m_{i}, \boldsymbol{\epsilon}\right)$ and $M\left(y, a, b_{i}, m_{i}, \boldsymbol{\epsilon}\right)$, respectively. Notice that when a country makes only its debt payment, the policies are $B\left(y, a, b_{i}, m_{i}, \boldsymbol{\epsilon}\right)=b_{i}$ and $M\left(y, a, b_{i}, m_{i}, \boldsymbol{\epsilon}\right)=m_{i}-1$, respectively. This will be the case, for example, when there is a debt rollover shock.

When the country has no access to credit markets $(a=1)$, the value of repayment is

$$
V^{P}\left(y, 1, b_{i}, m_{i}, \boldsymbol{\epsilon}\right)=u\left(y+b_{i}\right)+\beta E_{y^{\prime}, a^{\prime} \mid y, 1} E_{\epsilon^{\prime}} V^{G}\left(y^{\prime}, a^{\prime}, b_{i}, m_{i}-1, \epsilon^{\prime}\right)+\epsilon_{i}
$$

In this case, the country does not have the option to change the debt portfolio, and the choice reduces to either defaulting or making the promised payment and continuing next period with a debt characterized by the same payment and by a maturity that is one period shorter. Note that the expectation also contains future rollover risk. We assume that the probability of staying excluded from credit markets ( $a=1$ and $\left.a^{\prime}=1\right)$ is $\omega^{S S}$.

\section{Renegotiation and Restructuring}

This section explains how restructuring deals are endogenously determined in the model. We first discuss the main renegotiation setup used to derive the restructuring offers, and then we provide insight about the valuation of the restructured portfolio.

We follow Benjamin and Wright (2013) in assuming that after a default, the borrower and lenders have an opportunity to make a restructuring offer. This opportunity alternates stochastically between the borrower and lenders, and only one party can make an offer each period. In default, with probability $\lambda$, the lender $(\mathrm{L})$ offers a restructuring deal, and the sovereign borrower $(\mathrm{S})$, the country, decides whether to accept. Similarly, with probability $(1-\lambda)$, the sovereign has the option to make a restructuring offer to the lender. In both cases, the offer specifies a value that the new restructured portfolio must attain, $W$. Let $\tilde{H}\left(y, b_{i}, m_{i}, \epsilon, W\right)$ be the policy function that describes whether the offer is made by the country or accepted by the country in case that the lender made the offer (mathematically, it is exactly the same function). It takes value one if the offer is made/accepted and zero otherwise. The lenders make the restructuring offer before the values of the $\epsilon$ shocks are realized or observed by the borrower. Thus, when making the offer, lenders take the expectation over $\epsilon$ shocks and face a probability of acceptance, $E_{\epsilon} \tilde{H}\left(y, b_{i}, m_{i}, \epsilon, W\right)$, which is continuous and decreasing with respect to the value of the offer, $W$.

\section{A. How Is W Determined?}

If the Country Makes the Offer.-In this case, the country must decide whether to make an offer or not. The lenders would only accept offers with market value larger than the current market value of debt in default; i.e., $W \geq-b_{i} q^{D}\left(y, b_{i}, m_{i} ; m_{i}\right)=\underline{W}$, where $q^{D}$ is the price of debt in default given the characteristics of the debt in default 
and current income $y$. Thus, if the country makes the restructuring offer, it will be such that the lender would be just indifferent between accepting or not; i.e.,

$$
W^{S}\left(y, b_{i}, m_{i}\right)=-b_{i} q^{D}\left(y, b_{i}, m_{i} ; m_{i}\right) .
$$

As we assume that if the country makes this offer the lender always accepts it, there is no point for the country to offer any larger value, and any smaller value will be definitely rejected by the lenders. However, recall that borrowers are not required to make the offer when they have the opportunity. The policy function described above is equal to one, i.e., $\tilde{H}\left(y, b_{i}, m_{i}, \epsilon, \underline{W}\right)=1$, if the country makes the offer and is zero otherwise.

If the Lender Makes the Offer.-The lenders must take into account the probability of acceptance, $E_{\mathbf{\epsilon}} \tilde{H}\left(y, b_{i}, m_{i}, \boldsymbol{\epsilon}, W\right)$. As a result, in this case, the choice of the offer is

$$
\begin{aligned}
W^{L}\left(y, b_{i}, m_{i}\right)=\underset{W \leq-b_{i} \times m_{i}}{\arg \max }\left\{W \times E_{\boldsymbol{\epsilon}} \tilde{H}\left(y, b_{i}, m_{i}, \boldsymbol{\epsilon}, W\right)\right. & \\
& \left.+\left(1-E_{\epsilon} \tilde{H}\left(y, b_{i}, m_{i}, \boldsymbol{\epsilon}, W\right)\right) \times\left(-b_{i} q^{D}\left(y, b_{i}, m_{i} ; m_{i}\right)\right)\right\} .
\end{aligned}
$$

Lenders face an important trade-off. On the one hand, lenders prefer a larger market value of the new debt $(W)$. However, as $W$ increases, the probability that borrowers will accept the offer falls, as this reduces a borrower's value of restructuring relative to staying in default. Thus, lenders just maximize the expected value of a restructuring offer given its acceptance probability.

Note that we impose the constraint that the market value of the new debt portfolio cannot be larger than the face value of the debt in default. This constraint is the same as in Benjamin and Wright (2013) and is in line with bond acceleration clauses establishing that all future payments become due at the time of default.

The lender's offer decision rules for different income, different debt levels, and a maturity of ten years are shown in Figure 4. At low debt levels, the lenders ask for the largest possible recovery amount irrespective of output. As previously discussed, we consider offers not entailing negative haircuts, i.e., lenders cannot ask the country to repay more than the debt at the time of default, so the constraint $W \leq-b_{i} m_{i}$ is binding. As the defaulted debt and the lender's offer recovery value keep increasing, the target recovery value $W$ is constrained by the fact that higher $W$ would not be accepted by the country. Intuitively, the restructuring starts to become less attractive for a borrower with a low income level, so the probability that the country accepts the deal decreases (lower $H$ ), making it optimal for the lender to differentiate its target recovery value by income. In other words, the lender's recovery request is increasing with the country's output. Finally, for sufficiently large values of the debt in default, the constraint does not bind, and even with a constant probability of acceptance, the lender would not demand an increasing value of $W$, and the function becomes flat. The reason is that at some point, the market price of the new debt declines markedly with higher debt issuance, lowering the market value of the new debt portfolio. 


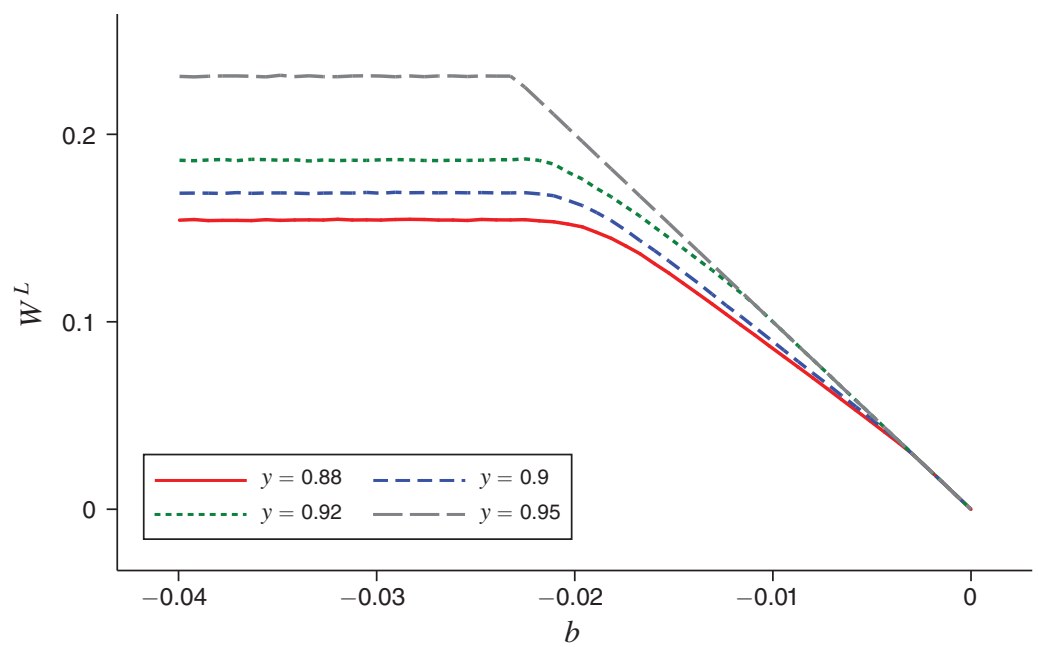

Figure 4. The Value of the Restructuring Deal When the Lender Makes the Offer, $W^{L}$

Note: The figure plots the lender's offer $\left(W^{L}(y, b, m)\right)$ for different income levels when the maturity of the defaulted debt is $m=10$ and the yearly payment of the defaulted debt is $b$ (x-axis).

\section{B. The Choice of Maturity in Restructuring}

Given a value $W$ agreed upon in the restructuring, the country chooses the new yearly payment, $b^{R}$; the new maturity, $m^{R}$; and a transfer of fresh money from the lenders to the country,

$$
\tau\left(y, W, b^{R}, m^{R}\right)=\underbrace{q^{E}\left(y, b^{R}, m^{R} ; m^{R}\right) \times\left(-b_{j}\right)}_{\text {resources raised with the new issuance }}-\underbrace{W}_{\begin{array}{c}
\text { amount agreed in } \\
\text { the restructuring }
\end{array}}=\tau(y, W, j),
$$

where the price of the debt being restructured, $q^{E}$, takes into account that the country will be excluded from credit markets next period with probability $\delta$, and we can replace $\left(b^{R}, m^{R}\right)$ with $j$ because the debt portfolio will be on the specified grid for debt maturity combinations.

Thus, the value of exiting restructuring with a deal of value $W$ is simply

$$
\begin{array}{rl}
\tilde{V}^{A}(y, W, \boldsymbol{\epsilon})=\max _{j} & u(y+\tau(y, W, j))+\epsilon_{j} \\
& +\beta E_{y^{\prime} \mid y} E_{\epsilon^{\prime}}\left[(1-\delta) V^{G}\left(y^{\prime}, 0, b_{j}, m_{j}, \boldsymbol{\epsilon}^{\prime}\right)+\delta V^{E}\left(y^{\prime}, b_{j}, m_{j}, \boldsymbol{\epsilon}^{\prime}\right)\right],
\end{array}
$$

subject to

$$
\tau^{R}(y, W, j) \geq 0,
$$

where the value function $V^{E}\left(y^{\prime}, b_{j}, m_{j}, \epsilon^{\prime}\right)$ is almost the same as $V^{G}\left(y^{\prime}, 1, b_{j}, m_{j}, \epsilon^{\prime}\right)$, with the only difference being that the probability of remaining excluded from the credit market in this case is $\delta$ instead of $\omega^{S S}$. 


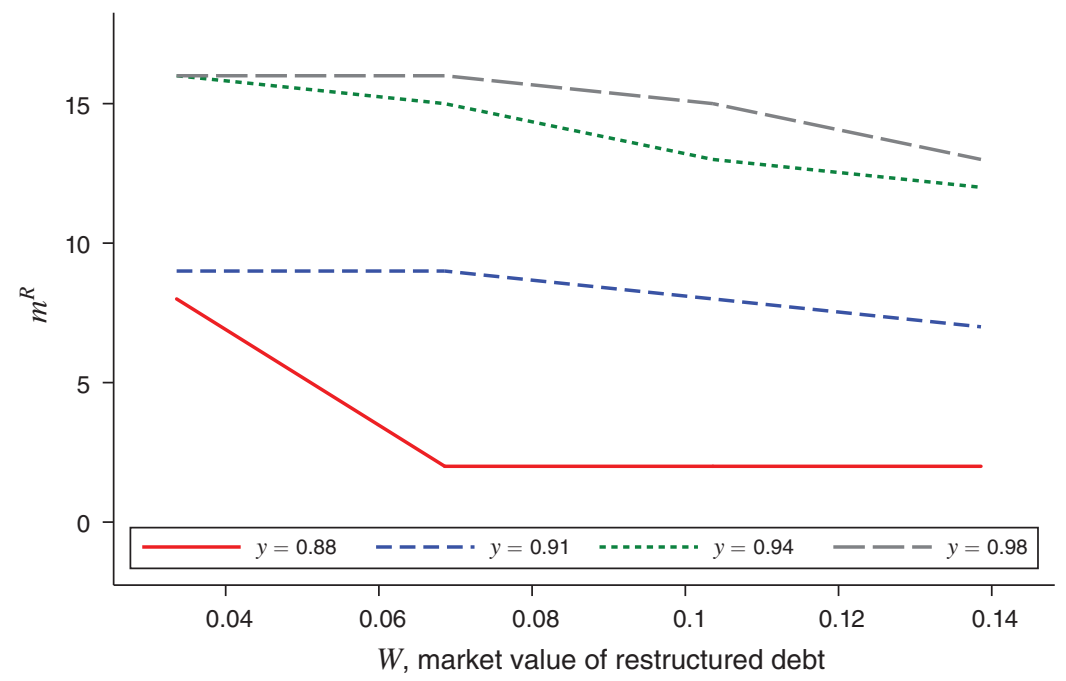

Figure 5. Choice of Maturity in Restructuring

Notes: The figure plots the optimal maturity choice in restructuring for different values of the restructured portfolio to satisfy $(W)$. The adjustment costs in restructuring and the realization of the $\epsilon$ shocks for the current period are set to their expected value (zero) for this figure.

Figure 5 shows that the optimal maturity chosen in restructuring, $m^{R}$, is decreasing in the market value of debt that was agreed upon in the restructuring, $W$, and increasing in income. The fact that maturity in restructuring is increasing in income is important in obtaining maturity extensions because income recovers from the time of default until the time of restructuring.

Next, we add the fact that lenders are concerned about both the market value of debt and the extra cost due to a reduction in the book value of debt. In this case, we can let the country choose the details of the restructurings deal, i.e., a reduction in $b$ or an increase in $m$, as long as the country compensates the lender for their extra cost, $\kappa \max \{x, 0\}$. Thus, the assumption simplifies the presentation without loss of generality. The country chooses the new yearly payment, $b^{R}$; the new maturity, $m^{R}$; and a transfer of fresh money from the lenders to the country, $\tau^{R}$, which is

$$
\tau^{R}(y, W, j, i)=q^{E}\left(y, b_{j}, m_{j} ; m_{j}\right) \times\left(-b_{j}\right)-W-\underbrace{\kappa \max \left\{\left|b_{i} \times m_{i}\right|-\left|b_{j} \times m_{j}\right|, 0\right\}}_{\text {regulatory cost of book value haircuts }} .
$$

The problem of choosing the portfolio remains the same except for two differences: (i) $\tau$ is replaced by $\tau^{R}$, and (ii) the current portfolio with the debt in default, $i$, is also a state variable. The solid black and dashed blue lines in Figure 6 show the optimal maturity chosen in restructuring, $m^{R}$, for the cases with and without the regulatory costs of book value losses. Clearly, when book value losses carry an extra cost, the maturity chosen in restructuring is larger. Thus, this force plays a role in generating maturity extensions.

Finally, to better understand the differences between the choice of maturity in restructuring and in normal times, assume that in the period before default-i.e., the 


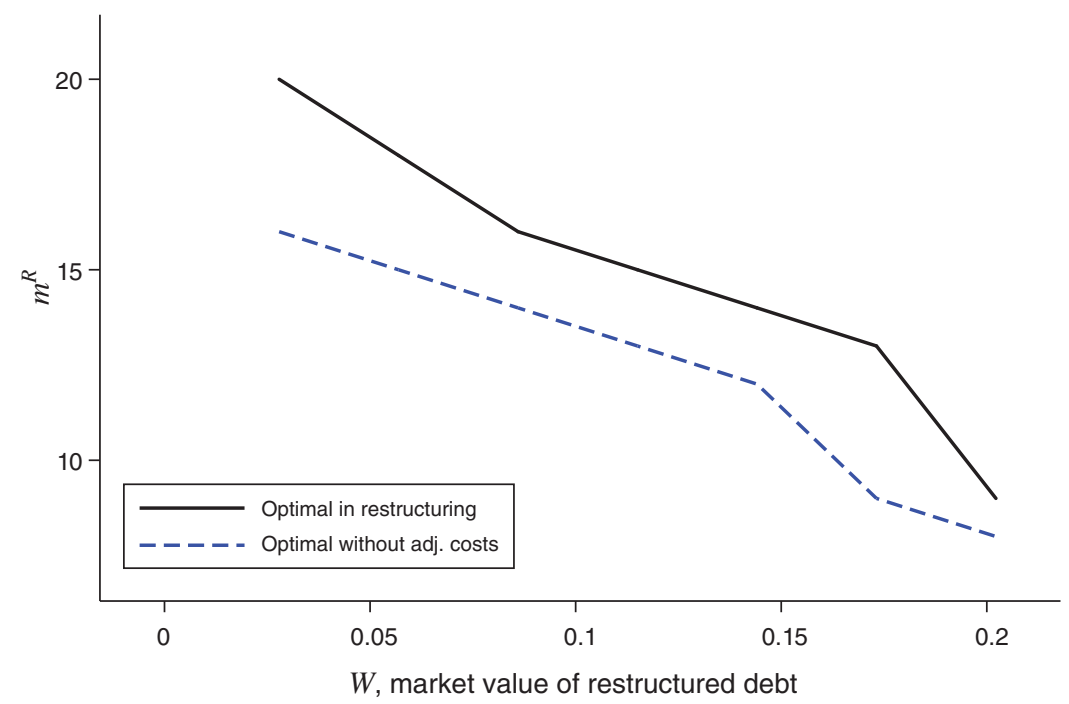

Figure 6. Optimization in Restructuring with and without the AdJustment Costs

Notes: The figure shows the optimal maturity in restructuring with and without the adjustment costs in the current period. The realizations of the $\epsilon$ shocks are set to their expected value (zero) for the current period. The income level is set at 0.93 , and the current maturity $(m)$ and debt level $(b)$ are set at 10 and -0.06 , respectively.

last time the country made a maturity choice - the state variables are the same as in the period of the restructuring deal. Would the choice of maturity be the same? We argue that the choice of maturity would be lower in restructuring, and as a result, maturity extensions would be negative. This result is an important force highlighted in AAHW: the debt-dilution incentives that exist during normal times are absent in restructuring.

To see this point, we compare two maturity options that achieve the same value $W$ of the restructured debt portfolio, and for simplicity, we abstract from book value costs (i.e., $\kappa=0)$. In particular, with $m=3$, we find $b^{R}(3)$ such that $b^{R}(3) q\left(y, 0, b^{R}(3), 3 ; m^{R}\right)=W$, and with $m=10$, we find $b^{R}(10)$ such that $b^{R}(10) q\left(y, 0, b^{R}(10), 10 ; m^{R}\right)=W$. In restructuring, as both choices raise $W$, current consumption is the same, and the choice of $m^{R}$ depends only on how it affects future utility. By contrast, in normal times (also abstracting from portfolio adjustment costs), dilution adds an effect on current consumption. If $m^{R}=3$, current consumption is

$$
c=y+b+q\left(y, 0, b^{R}(3), 3 ; m-1\right) b-W,
$$

and if $m^{R}=10$, current consumption is

$$
c=y+b+q\left(y, 0, b^{R}(10), 10 ; m-1\right) b-W .
$$




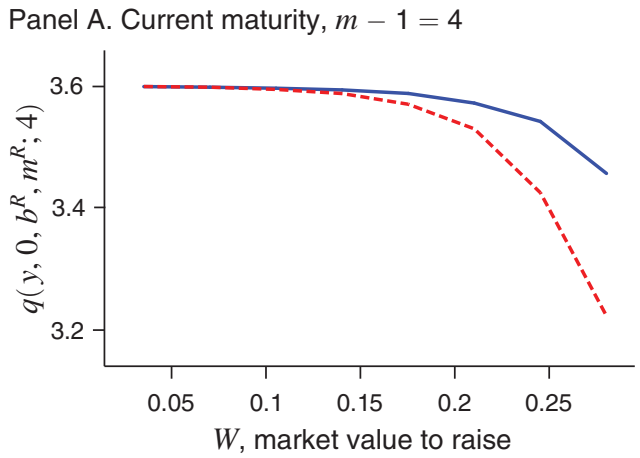

Panel B. Current maturity, $m-1=9$

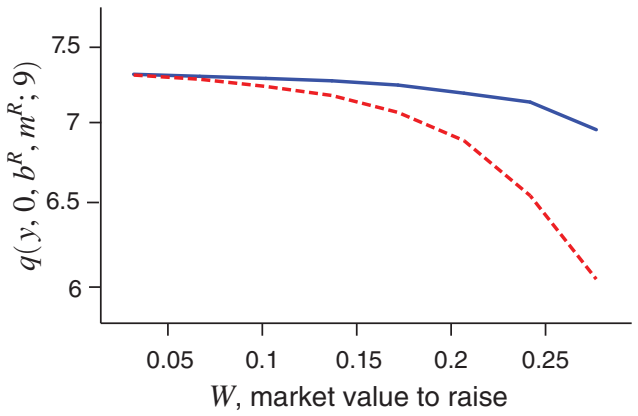

Figure 7. Closing Price with Alternative Maturity Choices

Notes: The value of income, $y$, is set at 0.96. For each $W$ and $m^{R}, b^{R}\left(m^{R}, W\right)$ is such that $b^{R}\left(m^{R}, W\right) q\left(y, 0, b^{R}\left(m^{R}, W\right), m^{R} ; m^{R}\right)=W$; that is, the market value of issuing $\left(b^{R}, m^{R}\right)$ is equal to $W$. The $\mathrm{y}$-axis gives the unit price of the old debt after making the coupon payment $b$ and after issuing $\left(b^{R}, m^{R}\right)$ for alternative maturities of the old debt, $m-1=4$ (panel A) and $m-1=9$ (panel B).

Clearly, in terms of consumption today, these two options are not equal. Consumption would be larger for the maturity choice with the lower price of the old debt, $q \cdot \cdot^{18}$ Since shorter maturity decreases debt dilution, short-term debt has a higher price, and current consumption would be lower with shorter maturity. Thus, in normal times, there is an extra force that favors longer maturity than in restructuring. This leads to a shortening of maturity in restructuring.

To illustrate how the value of $q$ in the expressions above looks for different maturities, in Figure 7, we plot the values of $q$ for $m^{R}=3$ and $m^{R}=10$ and for two alternative values of $m-1 .{ }^{19}$ As expected, because short maturity reduces the risk of debt dilution, we find that $q\left(y, 0, b^{R}(3), 3 ; m-1\right)>q\left(y, 0, b^{R}(10), 10 ; m-1\right)$.

\section{The Value of a Country in Restructuring}

To express the value of a country in restructuring, it is convenient to specify the function $\tilde{V}^{R}$, which is the same in two cases: (i) a country that received an offer of $W$, deciding whether to accept it and (ii) a country considering whether to make an offer of $W$.

This function is $\tilde{V}^{R}(y, W, i, \boldsymbol{\epsilon})=\max \left\{V^{D}\left(y, b_{i}, m_{i}, \epsilon_{\mathcal{J}+1}\right) ; \tilde{V}^{A}(y, W, i, \boldsymbol{\epsilon})\right\}$. Using the notation presented in the previous subsection, the value of a country in restructuring can be expressed as

$$
\begin{aligned}
V^{R}\left(y, b_{i}, m_{i}, \boldsymbol{\epsilon}\right)= & \lambda \tilde{V}^{R}\left(y, b_{i}, m_{i}, \boldsymbol{\epsilon}, W^{L}\left(y, b_{i}, m_{i}\right)\right) \\
& +(1-\lambda) \tilde{V}^{R}\left(y, b_{i}, m_{i}, \boldsymbol{\epsilon}, W^{S}\left(y, b_{i}, m_{i}\right)\right) .
\end{aligned}
$$

\footnotetext{
${ }^{18}$ Remember that with debt, $b$ is negative.

${ }^{19}$ Note that in the comparison across maturities, the payments are for the same number of periods, $m-1$, and the equilibrium choices $b^{R}$ and $m^{R}$ are such that they raise a value $W$.
} 


\section{Equilibrium}

Given the world interest rate $r$ and lenders' risk neutrality, the price of the country's debt must be consistent with zero expected discounted profits. The price of a nondefaulted bond of maturity $m_{i}>0$ of a country with income $y$, yearly debt payment $-b_{j}$, and portfolio maturity $m_{j}>0$ can be represented by

$$
\begin{aligned}
& q\left(y, a, b_{j}, m_{j} ; m_{i}\right) \\
&=\frac{E_{y^{\prime}, a^{\prime} \mid y, a} E_{\epsilon^{\prime}}}{1+r}\left\{\left(1-D\left(y^{\prime}, a^{\prime}, b_{j}, m_{j}, \epsilon^{\prime}\right)\right)\right. \\
& \times\left(1+q\left(y^{\prime}, a^{\prime}, B\left(y^{\prime}, a^{\prime}, b_{j}, m_{j}, \boldsymbol{\epsilon}^{\prime}\right), M\left(y^{\prime}, a^{\prime}, b_{j}, m_{j}, \boldsymbol{\epsilon}^{\prime}\right) ; m_{i}-1\right)\right) \\
&\left.\quad+D\left(y^{\prime}, a^{\prime}, b_{j}, m_{j}, \boldsymbol{\epsilon}^{\prime}\right) q^{D}\left(\min \left\{y^{\prime}, \pi^{D}\right\}, b_{j}, m_{j} ; m_{i}\right)\right\} .
\end{aligned}
$$

After the country repays one unit today, the valuation of debt maturing in $m_{i}-1$ periods depends on the expectation about future payoffs associated with repayments, reflected in future prices when $D=0$, and on future payoffs in default states, in which the relevant price will be $q^{D}$ as explained below. Similarly, the price of debt used in restructuring is

$$
\begin{aligned}
& q^{E}\left(y, b_{j}, m_{j} ; m_{i}\right) \\
& =\delta \frac{E_{y^{\prime} \mid y} E_{\epsilon^{\prime}}}{1+r}\left\{\left(1-D^{E}\left(y^{\prime}, b_{j}, m_{j}, \boldsymbol{\epsilon}^{\prime}\right)\right)\left(1+q^{E}\left(y^{\prime}, b_{j}, m_{j}-1 ; m_{i}-1\right)\right)\right. \\
& \left.+D^{E}\left(y^{\prime}, b_{j}, m_{j}, \boldsymbol{\epsilon}^{\prime}\right) q^{D}\left(\min \left\{y^{\prime}, \pi^{D}\right\}, b_{j}, m_{j} ; m_{i}\right)\right\} \\
& +(1-\delta) \frac{E_{y^{\prime} \mid y} E_{\epsilon^{\prime}}}{1+r}\left\{\left(1-D\left(y^{\prime}, 0, b_{j}, m_{j}, \epsilon^{\prime}\right)\right)\right. \\
& \times\left(1+q\left(y^{\prime}, 0, B\left(y^{\prime}, 0, b_{j}, m_{j}, \boldsymbol{\epsilon}^{\prime}\right), M\left(y^{\prime}, 0, b_{j}, m_{j}, \boldsymbol{\epsilon}^{\prime}\right) ; m_{i}-1\right)\right) \\
& \left.+D\left(y^{\prime}, 0, b_{j}, m_{j}, \boldsymbol{\epsilon}^{\prime}\right) q^{D}\left(\min \left\{y^{\prime}, \pi^{D}\right\}, b_{j}, m_{j} ; m_{i}\right)\right\} .
\end{aligned}
$$

The price per unit of yearly payment $b_{j}$ in default is $q^{D}$ and has the expression

$$
\begin{aligned}
q^{D}\left(y^{\prime}, b_{j}, m_{j} ; m_{i}\right) & \\
=\frac{E_{y^{\prime} \mid y}}{1+r}\left\{q^{D}\left(\min \left\{y^{\prime}, \pi^{R}\right\}, b_{j}, m_{j} ; m_{i}\right)\right. & \\
+ & \lambda E_{\epsilon^{\prime}} H^{L}\left(y^{\prime}, b_{j}, m_{j}, \epsilon^{\prime}\right) \\
& \left.\times\left[\frac{1}{-b_{j}} \frac{q^{*}\left(m_{i}\right)}{q^{*}\left(m_{j}\right)} W^{L}\left(y^{\prime}, b_{j}, m_{j}\right)-q^{D}\left(\min \left\{y^{\prime}, \pi^{R}\right\}, b_{j}, m_{j} ; m_{i}\right)\right]\right\} .
\end{aligned}
$$


A lender with promises up to $m_{i}$ years would obtain $q^{D}\left(y, b_{j}, m_{j} ; m_{i}\right)$ per dollar of yearly promises that she holds. This per-dollar payment, or bond price, depends on the total debt defaulted upon, which in this case is $b_{j}$ yearly payments for $m_{j}$ years. One key aspect affecting the cost of borrowing at different maturities is how the total repayment made by the country, $W^{L}\left(y^{\prime}, b_{j}, m_{j}\right)$, is divided across bondholders. The simplest part is reflected in the fraction $1 /-b_{j}$. A bondholder entitled to one unit of yearly payments receives one over the total yearly payments promised. Similarly, $W^{L}$ is distributed across lenders holding bonds of different maturity using the ratio $q^{*}\left(m_{i}\right) / q^{*}\left(m_{j}\right)$, which means that later payments are discounted at the risk-free rate. 20

\section{Calibration and Evaluation}

\section{A. Calibration and Fit of Targeted Moments}

We solve the model numerically. Most parameters are calibrated following the literature or estimated directly from the data. The remaining parameters are jointly calibrated to capture key features of the data.

We calibrate the model to a yearly frequency. Households in the economy have a constant relative risk aversion (CRRA) utility with risk aversion coefficient $\gamma$, which is set at 2 , a standard value in the literature. The maximum possible maturity is 20 years, which is significantly larger than the typical maturities observed for emerging markets. ${ }^{21}$ We set the yearly risk-free interest rate to 4.2 percent to match the long-run average of the real 10-year US Treasury bonds yield. ${ }^{22}$ The standard deviation of the income shock is set to 0.019 , and the persistence is set to 0.86 , to replicate the yearly detrended GDP per capita process for Colombia as estimated in Sánchez, Sapriza, and Yurdagul (2018).

We set the regulatory cost of book value losses at 3 percent, $\kappa=0.03$. As explained in Section ID, this is a relatively low value considering that banks (lenders) may raise capital to remedy its severe shortfall at the time the sovereign defaults. Thus, we can associate this additional cost of book value losses to the banks' cost of raising capital.

Similarly, the value of the probability of remaining excluded after restructuring is set at 70 percent, $\delta=0.7$, to match the estimation of this probability using the data from Cruces and Trebesch (2013) as presented in Figure 3 in Section ID.

Using the definition of sudden stop from Comelli (2015) and controlling by fluctuations in the availability of credit due to the country's own conditions, we estimate that the probabilities of sudden stop are $\omega^{N}=0.12$ and $\omega^{S S}=0.42 .{ }^{23}$ These events

\footnotetext{
${ }^{20}$ Alternatively, we could have used the ratio $m_{i} / m_{j}$, but this expression would not take into account the timing of payments. We used that ratio in a previous version of this paper, and the main results did not change.

${ }_{21}^{1}$ Our results are robust to allowing for longer maximum maturities.

${ }^{22}$ Average of annualized monthly nominal yields minus PCE inflation between 1980 and 2010.

${ }^{23}$ Alternative ways of modeling exogenous variation in the availability of credit include adding risk-averse pricing kernels, as proposed for instance by Lizarazo (2013), or to introduce exogenous variations in the risk-free rate.
} 
TABle 5-Parameters and Fit OF TARgeted Statistics

\begin{tabular}{|c|c|c|c|c|}
\hline Parameter & Value & Basis & Target & Model \\
\hline Relative risk aversion, $\gamma$ & 2 & Standard & - & - \\
\hline Risk-free interest rate, $r$ & 0.042 & Average 10-year US rate & - & - \\
\hline Standard deviation income shocks & 0.019 & Estimated for Colombia & - & - \\
\hline Persistence of income & 0.86 & Estimated for Colombia & - & - \\
\hline Probability of remaining excluded, $\delta$ & 0.7 & See Section IIB & - & - \\
\hline Regulatory cost of book value losses, $\kappa$ & 0.03 & See Section IIB & - & - \\
\hline Probability of entering a sudden stop, $\omega^{N}$ & 0.12 & Estimated. See online Appendix & - & - \\
\hline Probability of staying in a sudden stop, $\omega^{S S}$ & 0.42 & Estimated. See online Appendix & - & - \\
\hline Discount factor, $\beta$ & 0.935 & Debt/output & $31 \%$ & $31.7 \%$ \\
\hline Output loss of entering default, $\pi^{D}$ & 0.90 & Default rate & $2.50 \%$ & $2.35 \%$ \\
\hline Output loss of staying in default, $\pi^{R}$ & 0.945 & Length of default, years & 2.30 & 2.32 \\
\hline Lender's offer probability, $\lambda$ & 0.55 & Mean SZ haircut & $32.8 \%$ & $34.1 \%$ \\
\hline Portfolio adjusted cost, $\alpha_{1}$ & 0.00005 & Average issuance costs & $0.2 \%$ & $1.1 \%$ \\
\hline Portfolio adjusted cost, $\alpha_{2}$ & 20 & $\Delta$ Debt/GDP near default & 22p.p. & 11p.p. \\
\hline Correlation parameter, $\rho$ & 0.25 & Standard deviation duration & 0.9 & 0.9 \\
\hline Variance parameter, $\sigma$ & 0.001 & Standard deviation debt/output & 8.0 & 9.5 \\
\hline
\end{tabular}

Notes: The data sources are in the online Appendix. The default rate in the data is based on Tomz and Wright $(2013,257)$, and the average haircut is based on data from Cruces and Trebesch (2013), where the sample excludes donor-funded restructuring and is restricted to high-quality data. Duration of a default episode is taken from Das, Papaioannou, and Trebesch $(2012,27)$. Issuance costs are taken as conservative estimates based on the statistics from Joffe (2015, figure 1). The change in debt-to-output at default relative to normal times is computed using the mean reported in Mendoza and Yue (2012, figure 1). See also their fact 3. Details on our computations are also in the online Appendix.

capture episodes in which many countries find it difficult to access international credit markets and are usually associated with an international financial crisis. ${ }^{24}$

We also introduce adjustment costs for changing the debt portfolio in order to capture issuance costs. Both changes in maturity and changes in the size of yearly payments are assumed to be costly. Therefore, the portfolio adjustment cost function has two parameters, $\alpha_{1}$ and $\alpha_{2}$, that are calibrated jointly with the remaining parameters of the model. ${ }^{25}$

Despite the joint parameter calibration, in Table 5, we attribute one moment to each parameter to indicate the moment we consider most informative of the parameter value. Table 5 summarizes the model parameters and the fit of their target statistics. Note that the level of the adjustment cost during normal times $\left(\alpha_{1}\right)$ is calibrated such that the equilibrium expenditures on the adjustment cost closely match available data on the cost of issuing debt. The curvature $\left(\alpha_{2}\right)$ prevents large increases in debt and a consumption boom in the period before default, so it is calibrated to the average increase in the debt-to-output level before default. ${ }^{26}$

There are only a few other parameters to calibrate: the discount factor, $\beta$; the thresholds of income in the default loss function, $\pi^{D}$ and $\pi^{R}$; the probability of lenders making an offer after default, $\lambda$; and the parameters determining the variance of

\footnotetext{
${ }^{24}$ The details of the estimation and results are presented in the online Appendix.

${ }^{25}$ We use the functional form $\chi\left(b, m, b^{\prime}, m^{\prime}\right)=\alpha_{1} \exp \left(\alpha_{2}\left(\frac{m+m^{\prime}}{2}\left|b-b^{\prime}\right|-\frac{b+b^{\prime}}{2}\left|m-m^{\prime}\right|\right)\right)-\alpha_{1}$, where $-b$ and $m$ are the level and maturity of the debt portfolio, respectively, after making the current payment and $-b^{\prime}$ and $m^{\prime}$ are those of the newly issued debt.

${ }^{26}$ See the discussion in Hatchondo, Martinez, and Sosa-Padilla (2016), who impose an upper limit on the spread. We prevent this behavior with the curvature of the adjustment cost function.
} 
the $\epsilon$ shocks, $\rho$ and $\sigma$. The distribution of these shocks is assumed to be a Generalized Extreme Value, as discussed in Section VIII.

As is standard in the literature, $\beta$ and $\pi^{D}$ are calibrated to replicate the debt-to-output ratio and the default rate. The parameter $\pi^{R}$ determines how much income recovers in the time between default and restructuring. As shown by Benjamin and Wright (2018), this income recovery is important to determine the length of default. As a consequence, we choose this moment as a target.

The probability of lenders making an offer after default, $\lambda$, directly affects the value of the haircut. The values of $\rho$ and $\sigma$ must be positive for the computational benefits of using the extreme value shocks to apply. We calibrate these parameters to match the standard deviation of duration and the standard deviation of the debt-to-output ratio because, as we show in Table 14 in Section VIIIC, these moments are directly affected by $\rho$ and $\sigma$. More importantly, we show that with this calibration, the $\epsilon$ shocks are not a significant source of defaults, nor do they materially influence the maturity and debt choices (see Table 15 and Figure 13).

The model replicates very well most targeted moments, though it generates a default rate that is lower than the target $(2.35$ percent versus 2.5 percent $)$ and a lower increase in the debt-to-output ratio leading into a default (11 p.p. versus 22 p.p.).

\section{B. Fit of Nontargeted Moments}

Our model can closely match several key nontargeted empirical stylized facts of emerging markets. For exposition purposes, we divide these statistics into three groups and compare model-generated moments with those of three well-known emerging-market economies. First, as illustrated in Table 6, our model closely captures the business cycles moments commonly discussed in the literature of sovereign default, such as the volatility of consumption relative to the volatility of output, which exceeds a value of one both in the data and the model; the correlation of consumption with output, which is high and positive both in the model and the data; the correlation of the trade balance with output, which is mild both in the model and in the sample data; and part of the volatility of the trade balance relative to the volatility of output.

Second, our model statistics also closely mimic the mean sovereign debt maturity and duration found in the data as well as their cyclical behavior (Table 6). ${ }^{27}$ The model delivers a maturity of 6.20 years and a duration of 3.43 years, only slightly lower than the average sample values. Additionally, the model generates the reduction of debt maturity and duration found in the data during bad times. During bad times, both debt maturity and duration in the model are about 15 percent lower than their averages. Our model is also able to capture the positive correlation between maturity and duration with output that is generally found in the data.

\footnotetext{
${ }^{27}$ Consistent with the data, for the model we use the Macaulay definition of debt duration. See the online Appendix for definitions of debt duration and yield spreads.
} 
Table 6-Fit of Key Nontargeted Moments

\begin{tabular}{|c|c|c|c|c|c|}
\hline Statistics & Brazil & Chile & Colombia & Mexico & Model \\
\hline $\operatorname{std}(\log (c)) / \operatorname{std}(\log (y))$ & 1.30 & 1.47 & 1.15 & 1.59 & 1.17 \\
\hline $\operatorname{std}(T B / y) / \operatorname{std}(\log (y))$ & 1.85 & 1.67 & 3.95 & 2.19 & 0.63 \\
\hline $\operatorname{corr}(\log (c), \log (y))$ & 0.40 & 0.84 & 0.82 & 0.67 & 0.84 \\
\hline $\operatorname{corr}(T B / y, \log (y))$ & 0.24 & -0.16 & 0.0 & -0.04 & 0.04 \\
\hline Duration (years) & 3.65 & 4.44 & 5.23 & 5.76 & 3.43 \\
\hline Duration (years, bad times) & 3.62 & 5.33 & 4.84 & 5.72 & 3.05 \\
\hline Maturity (years) & 6.47 & 5.53 & 9.62 & 11.43 & 6.20 \\
\hline Maturity (years, bad times) & 6.45 & 6.73 & 8.95 & 10.9 & 5.43 \\
\hline $\operatorname{corr}($ maturity, $\log (y))$ & 0.03 & -0.30 & 0.19 & 0.24 & 0.38 \\
\hline $\operatorname{corr}($ duration, $\log (y))$ & 0.06 & -0.32 & 0.34 & 0.02 & 0.47 \\
\hline 1-year spread (percent) & 1.93 & 0.48 & 0.82 & 1.32 & 0.77 \\
\hline 1-year spread (percent, bad times) & 1.80 & 0.74 & 0.87 & 1.28 & 1.53 \\
\hline 10 -year spread (percent) & 4.52 & 0.86 & 2.11 & 3.41 & 1.01 \\
\hline 10-year spread (percent, bad times) & 5.30 & 1.09 & 2.55 & 3.73 & 1.37 \\
\hline $\operatorname{corr}(1 Y S, \log (y))$ & -0.04 & -0.33 & -0.23 & -0.01 & -0.22 \\
\hline $\operatorname{corr}(10 Y S, \log (y))$ & -0.21 & -0.12 & -0.68 & -0.09 & -0.55 \\
\hline $10 Y S-1 Y S$ (percent) & 2.59 & 0.22 & 1.30 & 2.08 & 0.24 \\
\hline
\end{tabular}

Notes: The first-order moments are means for each country in the data. Bad times are the observations with detrended income below zero. The computation of moments for spreads in the model excludes the year before a default. See the online Appendix for computational details and data sources.

Third, as our study focuses on sovereign default risk, we also analyze sovereign bond yield spreads over risk-free debt instruments. ${ }^{28}$ The results in Table 6 suggest that while our framework somewhat underpredicts the level of the spreads, it captures well the dynamics of yield spreads for different bond maturities over the business cycle. Also, yield spreads for one-year and ten-year instruments are countercyclical, and spreads for short-term bonds are lower than those for longer-term instruments.

We next analyze regressions of SZ haircuts using model-simulated data. Table 7 shows that the model also reproduces the key forces determining haircuts. In particular, defaults with larger debt burdens exhibit larger haircuts upon restructuring. In our model, the key determinant of the value of restructured debt is the country's ability to pay, which, except for the cases for which the constraint in $W$ binds, is independent of the past. Therefore, holding other things constant, countries with more debt in the past obtain larger haircuts. The results also show that in the model, countries with higher income receive smaller haircuts. Lenders ask for a higher market value of debt in restructuring, $W$, from countries with higher income because these countries are less likely to default again and the probability that an offer is accepted for a given $W$ increases with income, given that the cost of staying in default is increasing in income for borrowers.

\footnotetext{
${ }^{28}$ The spread at each maturity is the difference between the yield on a zero-coupon bond with default risk and the yield on a bond with the same characteristics but with no default risk. We present the details of the model computations in the online Appendix.
} 
Table 7-Determinants of Haircuts in the Model

\begin{tabular}{lc}
\hline \hline & $\log ($ SZ haircut $)$ \\
\hline $\log ($ debt $\times$ maturity $/ y)$ & 1.612 \\
& $(0.347)$ \\
Cycle & -10.65 \\
& $(3.240)$ \\
\hline
\end{tabular}

Notes: Regressions are computed using simulated data from the model. Bootstrap standard errors, shown in parentheses, are computed using random samples (with replacement) of equal size as the one in the data in Cruces and Trebesch (2013), which we use in Section I.

TAble 8-Fit of Maturity Extensions

\begin{tabular}{lcr}
\hline \hline & Mean & SD \\
\hline Data maturity extensions, nonweighted (years) & 3.0 & 4.7 \\
Data maturity extensions, weighted (years) & 3.4 & 6.4 \\
Model maturity extensions (years) & 4.3 & 2.4 \\
\hline
\end{tabular}

Notes: The moments for SZ haircuts in the data are based on data from Cruces and Trebesch (2013). The weighted sample includes all episodes, which are weighted by debt in default. The nonweighted sample excludes donor-funded restructurings.

\section{Quantitative Evaluation of Maturity Extensions}

Our framework helps understand the maturity extensions documented for defaulting countries during distressed debt restructurings. In our setup, maturity extensions are endogenously determined as functions of the current income as well as the debt level and maturity at default. Our analysis is founded on the empirical evidence discussed earlier, which indicates that the extension of debt maturity is a commonly observed feature of distressed sovereign debt restructurings. As shown in the first column of Table 8 , the average maturity extension in the data is 3.4 or 3.0 years depending on whether observations are weighted by total debt restructured. Consistent with the data, the bottom row of the table illustrates that the average maturity extension in the model is 4.3 years.

Table 8 also shows that the model generates significant dispersion of maturity extensions. Moreover, the distribution of maturity extensions in the data and the model are very close as shown in Figure 8. Both distributions exhibit average and mode maturity extensions in the range of $(2,4)$ years and positive skewness.

The next subsections identify and analyze the key factors influencing maturity extensions in the data that we quantify in the model: (i) the recovery in income between default and restructuring, (ii) the probability of exclusion from financial markets after restructuring, (iii) the regulatory cost of book value haircuts, and (iv) debt dilution.

\section{A. Income Recovery after Default}

The unconditional evolution of income around a default episode in our model, illustrated in Figure 9. closely matches the corresponding pattern observed in the 


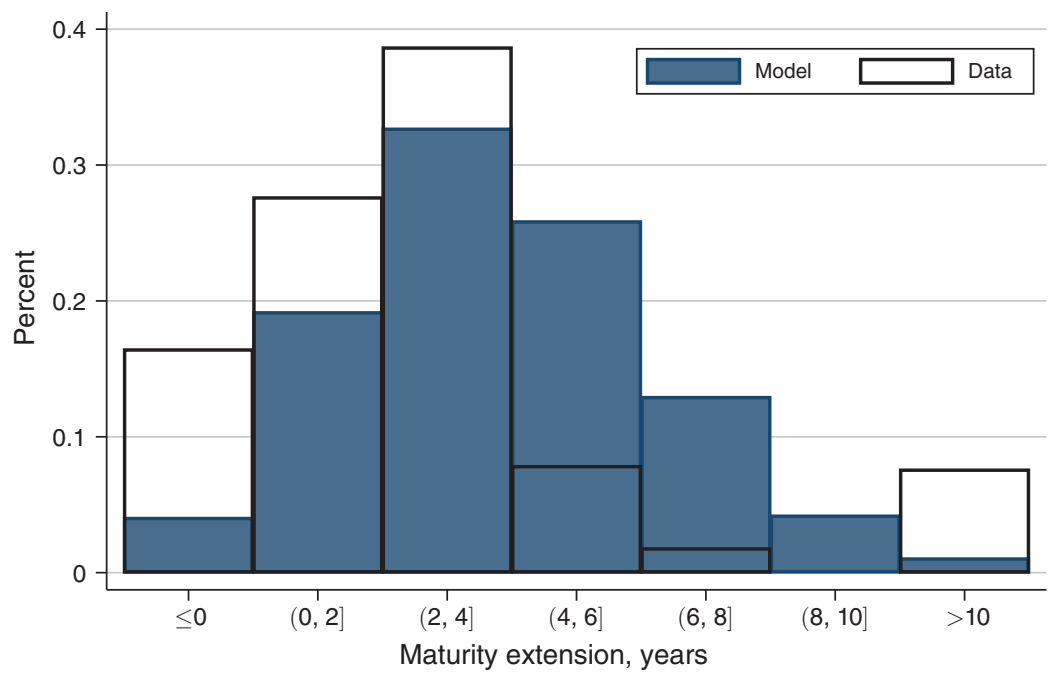

Figure 8. Distribution of Maturity Extensions

Note: The distribution of maturity extensions in the data is weighted by the restructured debt; excludes donorfunded restructurings.

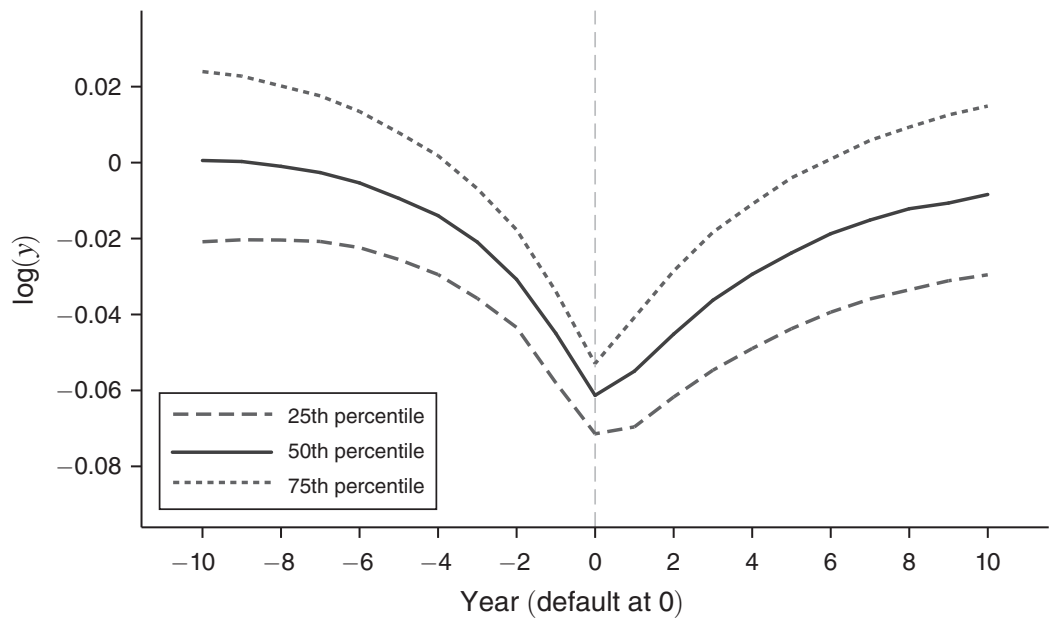

Figure 9. Behavior of Income around Default

Note: To construct this figure, we first isolate the corresponding statistics for $y=\{0,1,2, \ldots, 10\}$ before and after default episodes and then take the medians and other percentiles across these for each $y$.

data presented in Section ID. On average, countries default when output is about 6 percent below normal, and activity then gradually returns to normal values.

The evolution of income during the period between default and restructuring is shown in Table 9, the model counterpart to Table 4 in Section ID. While the increases in income in the model are not as pronounced as the large income gains documented in the data that lead to the observed high mean income changes, the median changes in the model and the data are more similar. 
Table 9-Income Recovery from Default until Restructuring, by Length (Years) of The Default Episode

\begin{tabular}{lcc}
\hline \hline & \multicolumn{2}{c}{ Income change } \\
\cline { 2 - 3 } & Mean & Median \\
\hline Length $>1$ & $0.3 \%$ & $0.3 \%$ \\
Length $>2$ & $1.2 \%$ & $1.3 \%$ \\
Length $>3$ & $1.6 \%$ & $1.7 \%$ \\
Length $>4$ & $1.7 \%$ & $1.7 \%$ \\
Length $>5$ & $1.7 \%$ & $1.7 \%$ \\
Length $>6$ & $1.7 \%$ & $2.0 \%$ \\
\hline
\end{tabular}

Notes: Default episodes from model-simulated data. Income changes conditional on length of the default episode. In the model, all defaults have length larger than one year. Percent change computed as the difference of the logs multiplied by 100 .

Table 10 - The Effect of Income Recovery between Default and Restructuring

\begin{tabular}{lccc}
\hline \hline & \multicolumn{3}{c}{ Baseline } \\
\cline { 2 - 4 } & All & No recovery & Recovery \\
& $(1)$ & $(2)$ & $(3)$ \\
\hline Average haircut, face value & 27.72 & 32.69 & 23.03 \\
Average haircut, SZ & 34.05 & 37.41 & 30.92 \\
Mean extension & 4.32 & 3.84 & 4.78 \\
Duration of default & 2.32 & 2.16 & 2.46 \\
\hline
\end{tabular}

Notes: "No recovery" corresponds to simulations with income at time of restructuring lower than at time of default. The "Recovery" column considers the opposite case, that is, results from simulations with income at time of restructuring higher than at time of default.

Table 10 shows other key moments of debt restructurings and how they are affected by income recovery. Column 1 in the table shows the benchmark results. Column 2 shows how the statistics change for those restructurings that occur when income is lower than at the time of default. Two results are worth highlighting in this case. First, debt haircuts are larger, in line with the relation between income and the market value of the debt restructuring offer $W$ discussed in Section IVA. Second, maturity extensions are shorter by about 0.5 years on average. The opposite is true for restructurings in which income has improved relative to the time of default as shown in column 3 .

To analyze the role of income for maturity extension, we present the value of maturity extensions by quintiles of income recovery using model-simulated data. The key result is that countries with larger income recovery receive longer maturity extensions. Recall that in our model, maturity is procyclical, so as income recovers, countries choose longer maturity extensions. Figure 10 shows this positive correlation between the income recovery (red bars) and the extension of maturity (blue bars), which results from model simulations.

\section{B. Exclusion after Restructuring}

Countries do not immediately access credit markets following a distressed debt restructuring. Table 11 shows restructuring statistics for alternative values 


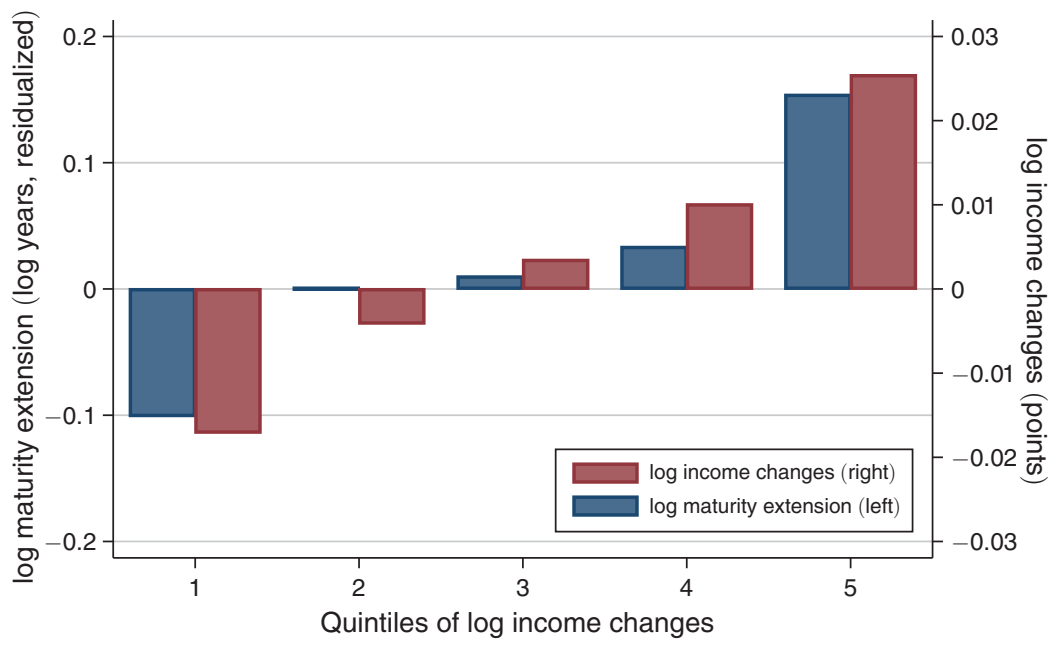

Figure 10. Income Recovery and Maturity Extensions

Notes: The graph shows the relationship between maturity extensions (in deviations from the mean) and changes in log income between default and restructuring (in deviations from the mean) for default episodes from model-simulated data. Each bar shows the mean value of the variable for each of the five groups. The five groups correspond to the quintiles of the log change in income.

Table 11 - The Effect of Exclusion after Restructuring, $\delta$

\begin{tabular}{lcccccc}
\hline \hline & Benchmark & & \multicolumn{4}{c}{ Changes in $\delta$} \\
\cline { 2 - 3 } \cline { 5 - 7 } & $\delta=0.7$ & & $\delta=0.12$ & $\delta=0.6$ & $\delta=0.75$ & $\delta=0.85$ \\
\hline Average haircut, face value & 27.72 & & 32.13 & 30.95 & 22.52 & 18.79 \\
Average haircut, SZ & 34.05 & & 26.07 & 30.98 & 39.06 & 43.63 \\
Mean extension & 4.32 & & 0.11 & 2.07 & 8.13 & 11.36 \\
Duration of default & 2.32 & & 2.52 & 2.35 & 2.27 & 2.21 \\
\hline
\end{tabular}

of $\delta$, which gives the probability of not being able to access credit markets after restructuring. We allow $\delta$ to range from 85 percent, which is higher than the number we calibrated to the data in Cruces and Trebesch (2013), to 12 percent, which is an interesting benchmark because it is equivalent to assuming that the probability of financial exclusion after a restructuring is the same as the probability of having an adverse debt-rollover shock in normal times. Note that the mean maturity extension decreases from 11.4 years to 0.11 years as $\delta$ decreases from 0.85 to 0.12 . Two main reasons help explain these results: First, as the expected number of periods during which countries will not be able to access financial markets is increasing in $\delta$, countries prefer to extend the maturity of their debt to spread the repayments over time. Second, the fact that countries cannot issue new debt for a few years after restructurings reduces the possibility of debt dilution and makes borrowing with long-term debt cheaper. 
Table 12-The Effect of the Regulatory Cost of Book Value Losses, $\kappa$

\begin{tabular}{lccccc}
\hline \hline & \multirow{2}{*}{ Benchmark } & & \multicolumn{3}{c}{ Alternative values of $\kappa$} \\
\cline { 2 - 2 } \cline { 5 - 7 } & $\kappa=0.03$ & & 0.00 & 0.02 & 0.05 \\
\hline Average haircut, face value & 27.72 & & 31.31 & 28.32 & 21.90 \\
Average haircut, SZ & 34.05 & & 35.20 & 34.55 & 35.62 \\
Mean extension & 4.32 & & 3.39 & 4.25 & 7.08 \\
Duration of default & 2.32 & & 2.28 & 2.30 & 2.33 \\
\hline
\end{tabular}

\section{Regulatory Costs of Book Value Haircuts}

The effects of changing the regulatory costs of book value haircuts are presented in Table 12. As expected, maturity extensions are increasing in $\kappa$, although the effect is more moderate than it was in the case for changes in $\delta$. Varying $\kappa$ from 5 percent to 0 percent reduces the maturity extension from 7.1 to 3.4 years. This change generates a substitution from face value reductions toward maturity extensions. The intuition for this result reflects the restructurings that were prevalent in the 1980s during the Latin American debt crisis, in which US banks restructured loans to countries favoring maturity extensions to avoid the cost that acknowledging losses would impose due to their need to satisfy capital requirements. Since these banks had very little buffer capital to absorb losses and were the largest holders of the defaulting countries' debt, a large value of $\kappa$ would be appropriate for such cases.

\section{The Effect of Debt Dilution}

The three features discussed in the previous subsections tend to generate positive maturity extensions in the model. In the absence of these forces, distressed debt restructuring episodes would be associated to negative debt maturity extensions, which we refer to as the AAHW result. To quantify the AAHW effect, we run the model after shutting down the three channels: from the simulations, we keep only the cases in which income did not recover; we set $\delta=0.12$, which is the probability of facing a debt-rollover shock (or sudden stop) in normal times; and we remove book value costs of restructuring, i.e., $\kappa=0$.

The effects of reducing $\delta$ and $\kappa$, together with no income recovery, are shown in Table 13. For comparison, column 1 replicates the baseline results. Column 2 analyzes the effects of reducing both $\delta$ and $\kappa$ but averages the statistical moments of interest over all possible income paths from the time of default until restructuring.

Compared to the benchmark results, in column 2, we see that the SZ haircuts are smaller but most importantly that on average, the maturity of the debt is not extended at all. Column 3 adds to this case the effects of an adverse income path (i.e., income does not recover from default). Thus, we shut down all the forces discussed so far that can generate positive maturity extensions. We see that in this case, the debt maturity extensions become negative, with a reduction in maturity of about seven months. In other words, we effectively find a negative extension as AAHW suggests. 
Table 13-The Effect of Debt Dilution

\begin{tabular}{lcccc}
\hline \hline & & \multicolumn{3}{c}{$\delta=0.12 ; \kappa=0.00$} \\
\cline { 3 - 5 } & Baseline all & $\begin{array}{c}\text { All } \\
(1)\end{array}$ & $\begin{array}{c}\text { No recovery } \\
(2)\end{array}$ & $\begin{array}{c}\text { Recovery } \\
(3)\end{array}$ \\
\hline Average haircut, face value & 27.72 & 33.69 & 41.91 & 25.57 \\
Average haircut, SZ & 34.05 & 27.86 & 34.35 & 21.47 \\
Mean extension & 4.32 & 0.05 & -0.64 & 0.73 \\
Duration of default & 2.32 & 2.47 & 2.39 & 2.54 \\
\hline
\end{tabular}

Notes: "No recovery" are simulations with income at time of restructuring lower than at time of default. It is the opposite for "Recovery."

Finally, while the response of debt maturity to changes in each of the three economic features leading to maturity extensions is nonlinear, when we analyze the relative strength of each of these economic forces, we observe that the financial exclusion after a restructuring (i.e., high values of $\delta$ ) has the strongest effect.

Moving from the economy with only debt dilution (Table 13) to the economy calibrated with regulatory costs of book value losses, exclusion after restructuring, and considering the episodes with income recovery (Table 10, column 3), we find that maturity extension varies by almost 5.4 years. Analyzing each driving force at a time, we find that 4.2 years are associated with the risk of exclusion being significantly higher than in normal times (Table 11), around 1.4 years are due to income recovery (Table 13, columns 3 and 4), and slightly less than 1 year is accounted for by regulatory costs (Table 12 ).

\section{Discrete Choices and Extreme Value Shocks}

The quantitative economic analysis in the previous sections was only possible thanks to the introduction of the $\epsilon$ shocks. As we describe next, these shocks are needed to make the computation of this interesting economic problem feasible since otherwise, we fail to achieve convergence in the value function iteration method used to solve the problem. From a computational point of view, these shocks are useful because they assign similar probabilities of being selected to choices that deliver similar utility. It is known that these situations are likely to arrive in models of maturity in points of the state space far from default.

An economic interpretation of these shocks is that they capture, in reduced form, costs and benefits of default, restructuring, and portfolio characteristics that are not related to our state variables (current debt portfolio and income). The shocks affecting more directly the default decision are now more common in the literature (see, for example, AAHW and Arellano, Bai, and Bocola 2017). They may capture additional costs or benefits of default, such as the perceptions of policymakers of the costs of default. ${ }^{29}$ The shocks that affect the choice of the debt portfolio can be interpreted for example as additional costs for the policymakers of

\footnotetext{
${ }^{29}$ A similar interpretation can be used for the shocks affecting whether the country accepts a restructuring deal.
} 
finding lenders willing to buy bonds of a particular maturity at equilibrium prices. More importantly, although the interpretation of these shocks may be interesting, we do not pursue this further because in our quantitative solution, the variance of these shocks is so small that they have negligible consequences for our results. In fact, as we show below, neither changing these variances by a factor of two nor redoing the simulations assuming the realizations of these shocks are zero has an impact in our variables of interest.

Given that our proposed solution method is new to this literature and may be useful for future research, the next subsections do the following: (i) explain how the value functions, policy functions, and equilibrium price functions can be reexpressed to greatly simplify the computation; (ii) show intuitively how these shocks smooth policy functions as their variance increases; and (iii) argue that these shocks do not affect a borrower's decision in a significant way, so they do not alter the quantitative results presented in the previous sections.

\section{A. The Ex Ante Problem}

From an ex ante point of view, the shocks $\epsilon$ make the default decision stochastic. In this model, a single borrower who has observed her own state variables and the realization of the $\epsilon$ shocks makes a unique deterministic decision on whether to default. However, by taking expectations over the $\epsilon$ shocks, we can view the default decision as probabilistic. We denote the probability of default as $\mathbf{D}\left(y, a, b_{i}, m_{i}\right)=E_{\boldsymbol{\epsilon}} D\left(y, a, b_{i}, m_{i}, \boldsymbol{\epsilon}\right)$. Similarly, the random component $\boldsymbol{\epsilon}$ makes the debt and maturity choice decisions random from an ex ante perspective. We denote as $\mathbf{G}_{y, a, b_{i}, m_{i}}\left(b_{j}, m_{j}\right)$ the probability distribution of choosing an amount of debt $-b_{j}$ and maturity $m_{j}$ for next period, conditional on not defaulting and on the current levels of income, asset, and maturity of the portfolio.

The next proposition shows how we can use the default probability and portfolio choice probability to get a more tractable expression for the bond prices.

PROPOSITION 1: Using the ex ante policy function $\mathbf{D}$ and $\mathbf{G}$, the price of the bond can be written as

$$
\begin{aligned}
& q\left(y, a, b_{j}, m_{j} ; m_{i}\right) \\
&=\frac{E_{y^{\prime}, a^{\prime} \mid y, a}}{1+r}\{\left(1-\mathbf{D}\left(y^{\prime}, a^{\prime}, b_{j}, m_{j}\right)\right) \\
& \times\left[1+\sum_{k=1}^{\mathcal{J}} q\left(y^{\prime}, a^{\prime}, b_{k}, m_{k} ; m_{i}-1\right) \mathbf{G}_{y^{\prime}, a^{\prime}, b_{j}, m_{j}}\left(b_{k}, m_{k}\right)\right] \\
&\left.\quad+\mathbf{D}\left(y^{\prime}, a^{\prime}, b_{j}, m_{j}\right) q^{D}\left(\min \left\{y^{\prime}, \pi^{D}\right\}, b_{j}, m_{j} ; m_{i}\right)\right\} .
\end{aligned}
$$

\section{PROOF:}

See Appendix A. 
Note the contrast between the price equation in Proposition 1 and the price equation (3), where we replaced the expectation over individual policy functions evaluated at each possible realization of the $\epsilon$ shock (a high-dimensional object) by the default and portfolio choice probabilities. If these probabilities are smooth functions, then the equilibrium price equation will also be smooth, a desirable property for the computation of the solution. Note in addition that the very large set of shocks $\epsilon$ is no longer present in the expression for the price equation, so we achieve smoothness without increasing the number of state variables in the model.

In a similar way as before, we define $\mathbf{H}^{\mathbf{L}}\left(y, b_{i}, m_{i}\right)=E_{\boldsymbol{\epsilon}} H^{L}\left(y, b_{i}, m_{i}, \boldsymbol{\epsilon}\right)$ as the probability that a restructuring offer made by the lender is accepted, and we let $\mathbf{V}^{\mathbf{G}}\left(y, a, b_{i}, m_{i}\right)=E_{\epsilon}\left[V^{G}\left(y, a, b_{i}, m_{i}, \boldsymbol{\epsilon}\right)\right]$ and $\mathbf{V}^{\mathbf{R}}\left(y, b_{i}, m_{i}\right)=E_{\epsilon}\left[V^{R}\left(y, b_{i}, m_{i}, \mathbf{\epsilon}\right)\right]$ be the ex ante (before observing the $\epsilon$ shocks) lifetime utilities in good credit status and in renegotiation, respectively.

We assume that the vector $\epsilon$ is i.i.d. over time and has the following joint cumulative density function:

$$
F(\mathbf{x})=\exp \left[-\left(\sum_{j=1}^{\mathcal{J}} \exp \left(-\frac{x_{j}-\mu}{\rho \sigma}\right)\right)^{\rho}-\exp \left(-\frac{x_{\mathcal{J}+1}-\mu}{\sigma}\right)\right],
$$

where $\mu$ is a parameter such that shocks have mean zero, $\sigma$ is a parameter that scales the variance of the shocks, and $\rho$ is a constant related to the correlation of the shocks in the debt and maturity choices. This function is known as the Generalized Extreme Value distribution and was pioneered by McFadden (1978) in the context of discrete choice models with random utility. ${ }^{30}$ By using the Generalized Extreme Value distribution, we model the decision problem as a Nested Logit, where the first nest captures the default decision and the second the debt portfolio choice. ${ }^{31}$

The next proposition shows how the additional assumptions further simplify the problem by delivering almost closed-form expressions for the value functions and policy function. To reduce the burden of notation, we do not report the expressions here but list them in the Appendix.

PROPOSITION 2: Under the assumptions described above, the expressions for the value functions $\left\{\mathbf{V}^{\mathbf{G}}, \mathbf{V}^{\mathbf{R}}\right\}$ and policy functions $\left\{\mathbf{D}, \mathbf{H}^{\mathbf{L}}, \mathbf{H}^{\mathbf{S}}, \mathbf{G}\right\}$ can be derived by solving the expectation over $\epsilon$ in closed form.

\section{PROOF:}

Appendix A.

\footnotetext{
${ }^{30}$ This type of distribution assumption has been extended to dynamic models and is widely used in different fields in economics, particularly structural labor, industrial organization, and international trade. The seminal works of Rust (1987), Pakes (1986), Wolpin (1984), and Miller (1984) have extended discrete choice models to dynamic settings. See also Caliendo, Dvorkin, and Parro (2019) for a recent quantitative application using a large dynamic general equilibrium model to study the effects of international trade on labor markets.

${ }^{31}$ It would be possible to create additional nests, but without additional information, it would be difficult to discipline this choice.
} 
Appendix A has the expressions for the functions in Proposition 2. The equations with the most intuitive economic interpretation are shown next in order to illustrate the method.

The probability of default can be expressed as

$$
\begin{aligned}
& \mathbf{D}\left(y, 0, b_{i}, m_{i}\right)= \\
& \frac{\exp \left(u\left(\min \left\{y, \pi^{D}\right\}\right)+\beta E_{y^{\prime} \mid \min \left\{y, \pi^{D}\right\}} \mathbf{V}^{\mathbf{R}}\left(\min \left\{y^{\prime}, \pi^{R}\right\}, b_{i}, m_{i}\right)\right)^{1 / \sigma}}{\left(\sum_{j=1}^{\mathcal{J}} \exp \left(u\left(c_{i j}(y)\right)+\beta E_{y^{\prime}, a^{\prime} \mid y, 0} \mathbf{V}^{\mathbf{G}}\left(y^{\prime}, a^{\prime}, b_{j}, m_{j}\right)\right)^{\frac{1}{\rho}}\right)^{\rho}+\exp \left(u\left(\min \left\{y, \pi^{D}\right\}\right)+\beta E_{y^{\prime} \mid \min \left\{y, \pi^{D}\right\}} \mathbf{V}^{\mathbf{R}}\left(\min \left\{y^{\prime}, \pi^{R}\right\}, b_{i}, m_{i}\right)\right)^{1 / \sigma}} .
\end{aligned}
$$

This probability adopts the logistic form that is common in dynamic discrete choice models. Default is more likely when the value of default is larger relative to the value of repaying. The variance of the shocks can play a relevant role in this probability. Specifically, when $\sigma$ is very large, the i.i.d. shocks will largely determine the choice, and economic conditions will not weigh much on the default decision. In the limit, there will be a 50 percent chance of default. When the shocks are very small (very small $\sigma$ ), the default decision will be almost completely determined by the economic conditions, and borrowers with the same state variables, $y, a, b_{j}, m_{j}$, will make the same decision.

Similarly, the probability of choosing a new debt level $b_{j}$ and maturity $m_{j}$ conditional on not defaulting, $\operatorname{Pr}\left(b^{\prime}=b_{j}, m^{\prime}=m_{j} \mid y, a, b_{i}, m_{i}\right) \equiv \mathbf{G}\left(b_{j}, m_{j} \mid y, a, b_{i}, m_{i}\right)$, has the expression

$$
\mathbf{G}_{y, 0, b_{i}, m_{i}}\left(b_{j}, m_{j}\right)=\frac{\exp \left(u\left(c_{i j}(y)\right)+\beta E_{y^{\prime}, a^{\prime} \mid y, 0}\left[\mathbf{V}^{\mathbf{G}}\left(y^{\prime}, a^{\prime}, b_{j}, m_{j}\right)\right]\right)^{\frac{1}{\rho \sigma}}}{\sum_{k=1}^{\mathcal{J}} \exp \left(u\left(c_{i k}(y)\right)+\beta E_{y^{\prime}, a^{\prime} \mid y, 0}\left[\mathbf{V}^{\mathbf{G}}\left(y^{\prime}, a^{\prime}, b_{k}, m_{k}\right)\right]\right)^{\frac{1}{\rho \sigma}}},
$$

which again says that the probability that a borrower selects a new debt maturity portfolio $j$ increases with the value associated to that particular portfolio.

We next discuss how these expressions for the default probability and the portfolio choice probability change smoothly with the state variables and how this depends on the parameters affecting the variance of the distribution.

\section{B. The Role of $\rho$ and $\sigma$}

We now provide some intuition regarding the effect of the i.i.d. $\epsilon$ shocks on the problem. The goal is to understand how the variance of the shocks modifies the original problem. ${ }^{32}$

The effect of the shocks can be seen in Figure 11, which shows the probability of default for the same income level but different magnitudes for the variance of the shock. With a small variance, the borrower tends to follow a single cutoff rule, defaulting with probability 1 for debt levels that are above a threshold. However, as the variance of the shock increases, this probability changes more gradually and smoothly with the levels of debt. The default probabilities enter in the equilibrium

\footnotetext{
${ }^{32}$ The numerical results in this section are just for illustration.
} 


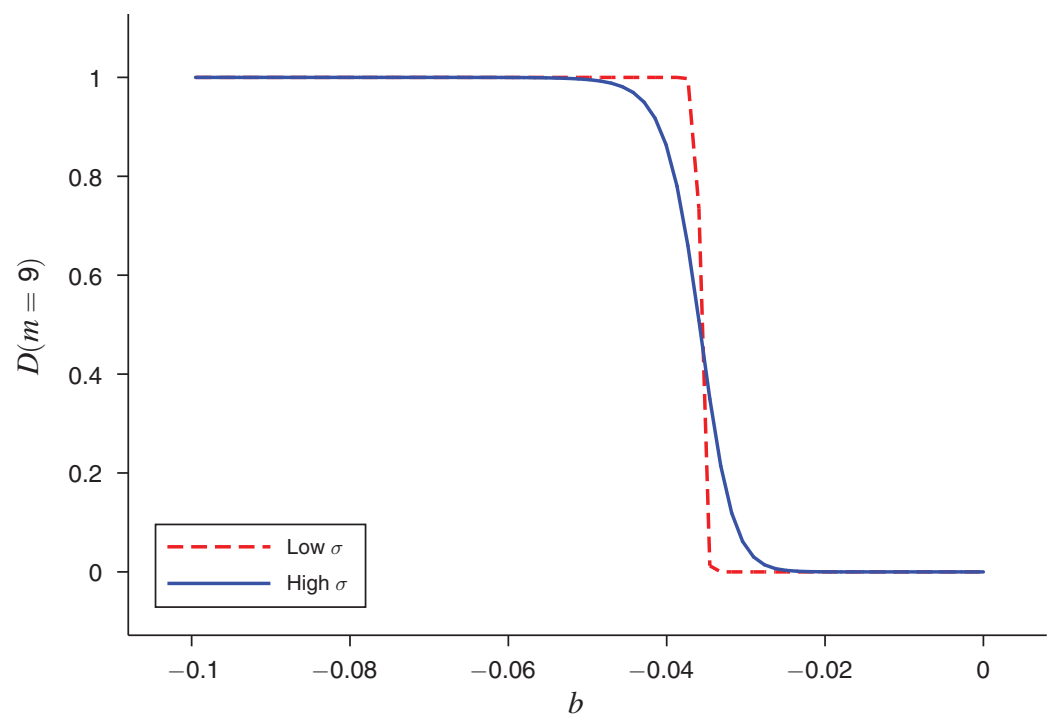

Figure 11. Probability of Default for Different Variances of $\epsilon$ Shocks
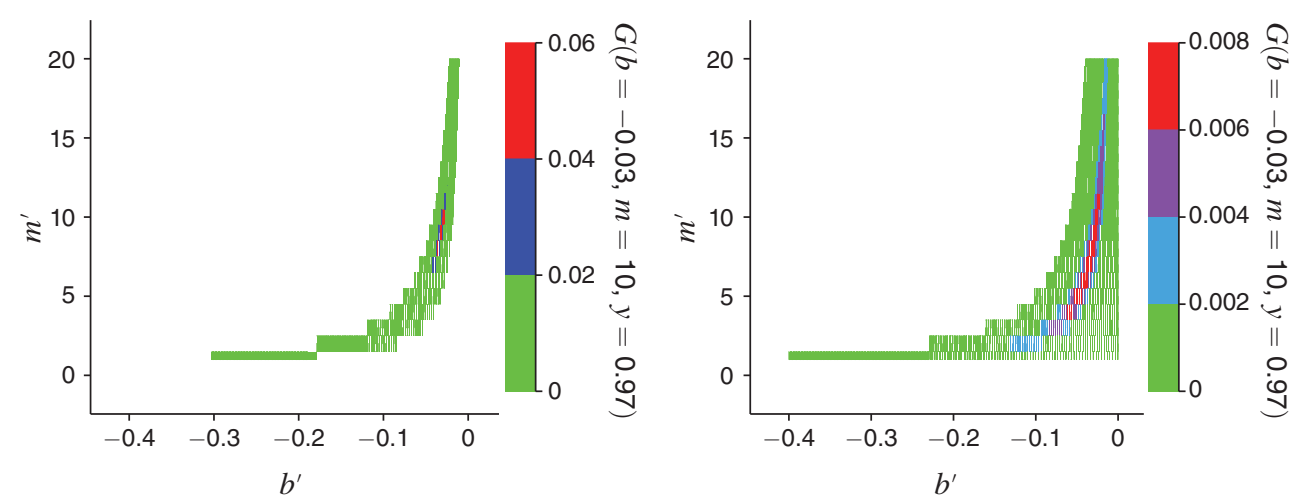

Figure 12. Debt Maturity Portfolio Probability for Different Variance of $\epsilon$ Shocks

price equations together with the other policy functions of the borrowers, so the smoother decision rules imply smoother price schedules.

The decision rules on portfolio choices for borrowers in good standing are shown in Figure 12. The figure is a color map depicting the probability of choosing a new debt maturity portfolio for a borrower. The shape of the figure resembles an indifference curve map, indicating that borrowers try to achieve a value of total borrowing and that they can do this with low payments for longer periods of time (longer maturity) or with higher payments for shorter periods (shorter maturity). The intensity of the colors indicates that borrowers prefer a particular combination, located in the center of the colored area, but there may be a dispersion around it due to the i.i.d. $\epsilon$ shocks. The comparison of the two panels in Figure 12 highlights how the portfolio choice is affected by the variance of the shocks. With a smaller variance, the probability of choosing a certain set of portfolios is highly concentrated as shown in the left panel. As the variance increases, the choices are more dispersed. 
The benefit of smooth decision rules is that in the algorithm that searches for an equilibrium, small changes from one iteration to the next should not cause large changes in the demand for different debt portfolios or prices. In this way, the iterative procedure to solve for the equilibrium tends to converge without major oscillations. These decision rules enter the valuation of a particular portfolio in the pricing equation. The $\epsilon$ shocks generate a smooth demand for a large variety of portfolios, even for borrowers in the same state.

\section{Quantitative Role of $\epsilon$ Shocks}

The $\epsilon$ shocks are computationally convenient, but they may also have implications for the behavior of the model. In Table 14, we show how some statistics change as we modify the value of the parameters of the distribution of the extreme value shocks, $\rho$ and $\sigma$. In particular, because these shocks affect the choices of debt and maturity, increasing their variance corresponds to increasing the standard deviation of the equilibrium duration, maturity, and debt-to-GDP ratio. Thus, these moments are informative of how large the variance of these shocks should be in the model, and we use them in our calibration strategy.

Note also that these extreme value shocks are independent over time, so increasing their variance lowers the autocorrelation of equilibrium duration, maturity, and the debt-to-GDP ratio. Finally, a larger variance of these shocks implies that default and debt maturity choices will be determined more by the realizations of $\epsilon$ and thus reduce the importance of, for example, income fluctuations in these choices. Thus, increasing their variance reduces the correlation of equilibrium maturity and duration with income.

But how important are $\epsilon$ shocks given our calibration? The results in Table 14 also suggest that at the current values, these shocks are not important determinants of default and indebtedness. To answer this question more directly, we proceed to compute the default and portfolio choices in what we call the $\epsilon$-zero model, where we set all realizations of every $\epsilon$ shock to zero. ${ }^{33}$

Table 15 compares the baseline model with the $\epsilon$-zero model. First, note that the default rate is almost the same, with a value of 2.35 percent and 2.36 percent in the baseline model and in the $\epsilon$-zero model, respectively.

Second, we show that not only are the default rates similar but, in most cases, the episodes of default are also the same across models. The rate of default using the episodes in which there is default is 2.23 percent in both models. As shown in the table, in only 0.12 percent +0.13 percent of the cases is the decision of default different across models, but because the changes are in the opposite direction, they offset, and the default rates are almost identical.

Finally, Figure 13 shows the statistical distributions of choices of maturity and the market value of the debt of the portfolios taken to the next period in our benchmark model and contrasts with those implied by shutting down $\epsilon$ shocks in the current period. The portfolio decisions are extremely similar.

\footnotetext{
${ }^{33}$ See the details on the implementation in the online Appendix.
} 
TABLE $14-\operatorname{RolE}$ OF $\sigma$ AND $\rho$

\begin{tabular}{lccccc}
\hline \hline & Baseline & $0.75 \times \sigma$ & $2 \times \sigma$ & $0.75 \times \rho$ & $2 \times \rho$ \\
\hline Default (percent) & 2.35 & 2.41 & 2.45 & 2.37 & 2.47 \\
(Debt $\times$ maturity)/GDP (percent) & 31.74 & 31.18 & 31.69 & 31.67 & 31.49 \\
Standard deviation duration & 0.89 & 0.85 & 1.04 & 0.85 & 1.04 \\
Standard deviation maturity & 1.99 & 1.92 & 2.40 & 1.89 & 2.42 \\
Standard deviation debt/GDP & 9.47 & 9.27 & 9.54 & 9.39 & 9.52 \\
Autocorrelation duration & 0.89 & 0.89 & 0.89 & 0.88 & 0.89 \\
Autocorrelation maturity & 0.87 & 0.86 & 0.87 & 0.86 & 0.87 \\
Autocorrelation debt/GDP & 0.90 & 0.90 & 0.89 & 0.90 & 0.89 \\
corr(maturity, $\log (G D P))$ & 0.38 & 0.40 & 0.31 & 0.40 & 0.31 \\
corr(duration, $\log (G D P))$ & 0.47 & 0.50 & 0.40 & 0.49 & 0.40 \\
\hline
\end{tabular}

Table 15-Default Rate (Percent) In the Model, with and without $\epsilon$ Shocks in the Current Period

\begin{tabular}{llccc}
\hline \hline & & \multicolumn{3}{c}{ Baseline model } \\
\cline { 3 - 5 } & & Default & No default & Total \\
\hline \multirow{2}{*}{-zero model } & Default & 2.23 & 0.13 & 2.36 \\
& No default & 0.12 & 97.52 & 97.64 \\
& Total & 2.35 & 97.65 & 100.00
\end{tabular}
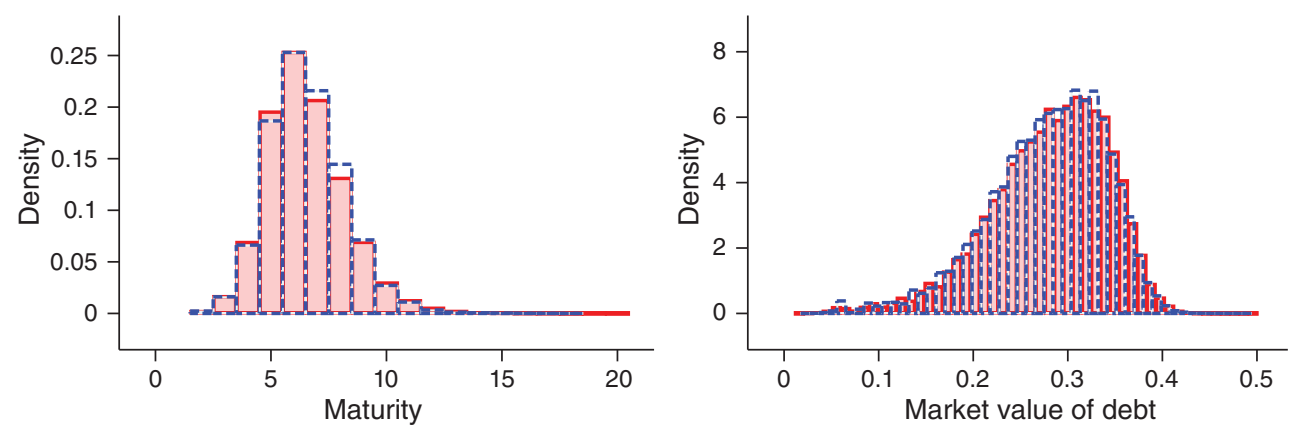

$\square$ Choice in the model

Figure 13. Distributions of Maturity and Market Value of Debt with Baseline and €-Zero Models

Note: The figures only show the cases without a debt rollover shock, i.e., $a=0$.

\section{Conclusion}

We present novel data documenting maturity extensions in distressed sovereign debt restructurings, and we build a quantitative model that replicates the key debt maturity and payment dynamics observed during these episodes. The model rationalizes the variation in haircuts and maturity extensions from restructurings across countries and mimics the business cycle properties of debt and the yield spread curve observed in the data. Our ability to solve this large quantitative model relies in good measure on the implementation of a novel solution method based on the dynamic discrete choice literature. 
Three mechanisms account for the maturity extensions observed in the data. First, as in the data, income in the model recovers between the time of default and the debt restructuring. Defaults occur when output is relatively low, and debt negotiation settlements generally happen once economic activity has improved, which implies a lower default probability and lower costs of borrowing. As debt maturity is procyclical, the output recovery between default and settlement means that the chosen maturity of the new debt at settlement is longer than the maturity at the time of default. Second, countries usually do not participate in financial markets in the years following a restructuring, either because the market interest rates are too high or because (an EU or IMF) conditionality provides incentives for austerity measures. This is key to offset the perverse incentives of debt dilution discussed by Aguiar et al. (2019) that would lead to a reduction in maturity at the time of default. Third, lenders typically face regulations that lead them to prefer restructurings that reduce book value losses, which for the same net present value of the new debt translate into longer maturity. The effect of these regulations has been documented for the Latin American debt crisis and has also played an important role during the most recent Greek sovereign debt restructuring. Finally, we quantify the contribution of each of these mechanisms to maturity extensions. When comparing an economy with only debt dilution to an economy calibrated with regulatory costs of book value losses, exclusion after restructuring, and considering the episodes with income recovery, we find that maturity extension varies by about 5.4 years. Analyzing each driving force at a time, we find that about 4.2 years are associated with the risk of exclusion being significantly higher than in normal times, around 1.4 years are due to income recovery, and slightly less than 1 year is accounted for by regulatory costs.

In this paper, we focused on understanding the main forces shaping haircuts and maturity extensions during restructurings but abstracted from normative considerations or the evaluation of different restructuring policies. While we believe that there is probably a role for policies to affect the outcomes of restructuring, as discussed by Fernández and Martin (2014) and Corsetti, Erce, and Uy (2018), we also think that the evaluation of alternative policies first requires a framework where restructurings are the result of an endogenous renegotiation process. In this paper, we tackle this first step and leave a normative analysis for future work.

\section{Appendix A. Proofs}

\section{PROOF OF PROPOSITION 1:}

We begin by noting that the price of a nondefaulted bond does not directly depend on $\epsilon$ but only indirectly through the borrowers' choices:

$$
\begin{aligned}
q\left(y, a, b_{j}, m_{j} ; m_{i}\right) & \\
=\frac{E_{y^{\prime}, a^{\prime} \mid y, a} E_{\epsilon^{\prime}}}{1+r}\{ & \left(1-D\left(y^{\prime}, a^{\prime}, b^{\prime}, m^{\prime}, \epsilon^{\prime}\right)\right) \\
& \times\left(1+q\left(y^{\prime}, a^{\prime}, B\left(y^{\prime}, a^{\prime}, b_{j}, m_{j}, \epsilon^{\prime}\right), M\left(y^{\prime}, a^{\prime}, b_{j}, m_{j}, \boldsymbol{\epsilon}^{\prime}\right) ; m_{i}-1\right)\right) \\
& \left.\times D\left(y^{\prime}, a^{\prime}, b_{j}, m_{j}, \epsilon^{\prime}\right) q^{D}\left(\min \left\{y^{\prime}, \pi^{D}\right\}, a, b_{j}, m_{j} ; m_{i}\right)\right\} .
\end{aligned}
$$


We can partition the sample space into countable, finite, and mutually exclusive events. These consist of the realizations of $\epsilon$ that lead to default and those realizations that lead to a particular $b_{k}, m_{k}$ choice. This is convenient since in this case, we can write the expectation of these events (or a function of them) as the sum of the possible realizations times the probability of each of these events.

We denote by $\mathbf{D}\left(y, a, b_{j}, m_{j}\right)$ the probability that the realizations of $\boldsymbol{\epsilon}$ are such that default is preferred in our model. In this case, lenders holding the bond obtain $q^{D}\left(y, b_{j}, m_{j}, m_{i}\right)$. The realizations of $\epsilon$ that lead to nondefault and to the specific bond $b_{k}, m_{k}$, being chosen have a probability which we denote by $\mathbf{G}_{y, a, b_{j}, m_{j}}\left(b_{k}, m_{k}\right)$. If borrowers make this particular choice the next period, they will face the bond price $q\left(y^{\prime}, a^{\prime}, b_{k}, m_{k} ; m_{i}-1\right)$. Taking into account all possible choices, we can characterize the expectation over $\epsilon$ in the previous equation to express the bond price as

$$
\begin{aligned}
q\left(y, a, b_{j}, m_{j} ; m_{i}\right) & \\
=\frac{1}{1+r} E_{y^{\prime}, a^{\prime} \mid y, a}[ & \left(1-\mathbf{D}\left(y^{\prime}, a^{\prime}, b_{j}, m_{j}\right)\right) \\
\times & {\left[1+\sum_{k=1}^{\mathcal{J}} q\left(y^{\prime}, a^{\prime}, b_{k}, m_{k} ; m_{i}-1\right) \mathbf{G}_{y^{\prime}, a^{\prime}, b_{j}, m_{j}}\left(b_{k}, m_{k}\right)\right] } \\
& \left.+\mathbf{D}\left(y^{\prime}, a^{\prime}, b_{j}, m_{j}\right) q^{D}\left(\min \left\{y^{\prime}, \pi^{D}\right\}, b_{j}, m_{j} ; m_{i}\right)\right] .
\end{aligned}
$$

\section{PROOF OF PROPOSITION 2:}

Using the notation introduced above and taking expectation over the $\epsilon$ shocks, the problem of the borrower for $a=0$ can be written as

$$
\begin{aligned}
& \mathbf{V}^{\mathbf{G}}\left(y, 0, b_{i}, m_{i}\right) \\
& \equiv E_{\boldsymbol{\epsilon}}\left[V^{G}\left(y, 0, b_{i}, m_{i}, \boldsymbol{\epsilon}\right)\right] \\
& =E_{\boldsymbol{\epsilon}} \max \left\{\left[V^{P}\left(y, 0, b_{i}, m_{i}, \boldsymbol{\epsilon}\right), V^{D}\left(\min \left\{y, \pi^{D}\right\}, 0, b_{i}, m_{i}, \epsilon_{\mathcal{J}+1}\right)\right]\right\} \\
& =E_{\boldsymbol{\epsilon}}\left[\operatorname { m a x } \left\{\max _{j \in\{1,2, \ldots, \mathcal{J}\}}\left\{\frac{\left(c_{i j}(y)\right)^{1-\gamma}}{1-\gamma}+\beta E_{y^{\prime}, a^{\prime} \mid y, 0} \mathbf{V}^{\mathbf{G}}\left(y^{\prime}, a^{\prime}, b_{j}, m_{j}\right)+\epsilon_{j}\right\} ;\right.\right. \\
& \left.\left.\quad \frac{\left(\min \left\{y, \pi^{D}\right\}\right)}{1-\gamma}+\beta E_{y^{\prime} \mid \min \left\{y, \pi^{D}\right\}} \mathbf{V}^{\mathbf{R}}\left(\min \left\{y^{\prime}, \pi^{R}\right\}, b_{i}, m_{i}\right)+\epsilon_{\mathcal{J}+1}\right\}\right]
\end{aligned}
$$

subject to

$$
\begin{aligned}
c_{i j}(y)= & y+b_{i}-q\left(y, 0, b_{j}, m_{j} ; m_{i}\right) b_{j} \\
& +q\left(y, 0, b_{j}, m_{j} ; m_{i}-1\right) b_{i}-\chi\left(b_{i}, m_{i}-1, b_{j}, m_{j}\right),
\end{aligned}
$$


and the problem of the borrower with a debt rollover shock can be written as

$$
\begin{aligned}
& \mathbf{V}^{\mathbf{G}}\left(y, 1, b_{i}, m_{i}\right) \\
& \equiv E_{\boldsymbol{\epsilon}}\left[V^{G}\left(y, 1, b_{i}, m_{i}, \boldsymbol{\epsilon}\right)\right] \\
& =E_{\boldsymbol{\epsilon}} \max \left\{\left[V^{P}\left(y, 1, b_{i}, m_{i}, \boldsymbol{\epsilon}\right), V^{D}\left(\min \left\{y, \pi^{D}\right\}, 1, b_{i}, m_{i}, \epsilon_{\mathcal{J}+1}\right)\right]\right\} \\
& =E_{\boldsymbol{\epsilon}}\left[\operatorname { m a x } \left\{\frac{\left(y+b_{i}\right)^{1-\gamma}+\beta E_{y^{\prime}, a^{\prime} \mid y, 1} \mathbf{V}^{\mathbf{G}}\left(y^{\prime}, a^{\prime}, b_{i}, m_{i}-1\right)+\epsilon_{i} ;}{1-\gamma},\right.\right. \\
& \left.\left.\qquad \frac{\left(\min \left\{y, \pi^{D}\right\}\right)}{1-\gamma}+\beta E_{y^{\prime} \mid \min \left\{y, \pi^{D}\right\}} \mathbf{V}^{\mathbf{R}}\left(\min \left\{y^{\prime}, \pi^{R}\right\}, b_{i}, m_{i}\right)+\epsilon_{\mathcal{J}+1}\right\}\right] .
\end{aligned}
$$

Similarly, the value of entering the restructuring stage is

$$
\begin{aligned}
& \mathbf{V}^{\mathbf{R}}\left(y, b_{i}, m_{i}\right) \\
& \equiv E_{\epsilon}\left[V^{R}\left(y, b_{i}, m_{i}, \epsilon\right)\right] \\
& =\lambda E_{\epsilon}\left[\operatorname { m a x } \left\{\frac{(y)^{1-\gamma}}{1-\gamma}+\beta E_{y^{\prime} \mid y} \mathbf{V}^{\mathbf{R}}\left(\min \left\{y^{\prime}, \pi^{R}\right\}, b_{i}, m_{i}\right)+\epsilon_{\mathcal{J}+1} ;\right.\right. \\
& +(1-\lambda) E_{\epsilon}\left[\operatorname { m a x } _ { j \in \tau ^ { R } ( y , W ^ { L } , j ) \geq 0 } \left\{\frac{\left.\left.\left.\left.(y)^{1-\gamma}+\tau_{j}^{R} b_{j}^{R}\right)^{1-\gamma}+\beta E_{y^{\prime} \mid y} \mathbf{V}^{\mathbf{G}}\left(y^{\prime}, 1, b_{j}^{R}, m_{j}^{R}\right)+\epsilon_{j}\right\}\right\}\right]}{1-\gamma} \mathbf{V}^{\mathbf{R}}\left(\min ^{1-\gamma}\left\{y^{\prime}, \pi^{R}\right\}, b_{i}, m_{i}\right)+\epsilon_{\mathcal{J}+1} ;\right.\right. \\
& \left.\left.\quad \max _{j \in \tau^{R}\left(y, W^{S}, j\right) \geq 0}\left\{\frac{\left(y-\tau_{j}^{R} b_{j}^{R}\right)}{1-\gamma}+\beta E_{y^{\prime} \mid y} \mathbf{V}^{\mathbf{G}}\left(y^{\prime}, 1, b_{j}^{R}, m_{j}^{R}\right)+\epsilon_{j}\right\}\right\}\right]
\end{aligned}
$$

We now use properties of the distribution of $\epsilon$ to simplify the previous expressions further and also obtain expressions for the policy 
functions (portfolio choice and default probabilities). ${ }^{34}$ For the case of $a=0$,

$\mathbf{V}^{\mathbf{G}}\left(y, 0, b_{i}, m_{i}\right)$

$$
\begin{aligned}
=\sigma \log [ & {\left[\sum_{j=1}^{\mathcal{J}} \exp \left(\frac{\left(c_{i j}(y)\right)^{1-\gamma}}{1-\gamma}+\beta E_{y^{\prime}, a^{\prime} \mid y, 0} \mathbf{V}^{\mathbf{G}}\left(y^{\prime}, a^{\prime}, b_{j}, m_{j}\right)\right)^{1 / \rho \sigma}\right)^{\rho} } \\
& \left.+\exp \left(\frac{\left(\min \left\{y, \pi^{D}\right\}\right)^{1-\gamma}}{1-\gamma}+\beta E_{y^{\prime} \mid \min \left\{y, \pi^{D}\right\}} \mathbf{V}^{\mathbf{R}}\left(\min \left\{y^{\prime}, \pi^{R}\right\}, b_{i}, m_{i}\right)\right)^{1 / \sigma}\right] .
\end{aligned}
$$

And for $a=1$,

$\mathbf{V}^{\mathbf{G}}\left(y, 1, b_{i}, m_{i}\right)$

$=\sigma \log \left[\exp \left(\frac{\left(y+b_{i}\right)^{1-\gamma}}{1-\gamma}+\beta E_{y^{\prime}, a^{\prime} \mid y, 1} \mathbf{V}^{\mathbf{G}}\left(y^{\prime}, a^{\prime}, b_{i}, m_{i}-1\right)\right)^{1 / \sigma}\right.$

$$
\left.+\exp \left(\frac{\left(\min \left\{y, \pi^{D}\right\}\right)^{1-\gamma}}{1-\gamma}+\beta E_{y^{\prime} \mid \min \left\{y, \pi^{D}\right\}} \mathbf{V}^{\mathbf{R}}\left(\min \left\{y^{\prime}, \pi^{R}\right\}, b_{i}, m_{i}\right)\right)^{1 / \sigma}\right],
$$

while the value of entering the restructuring stage is

$$
\begin{aligned}
& \mathbf{V}^{\mathbf{R}}\left(y, b_{i}, m_{i}\right) \\
& =\lambda \sigma \log \left[\exp \left(\frac{(y)^{1-\gamma}}{1-\gamma}+\beta E_{y^{\prime} \mid y} \mathbf{V}^{\mathbf{R}}\left(\min \left\{y^{\prime}, \pi^{R}\right\}, b_{i}, m_{i}\right)\right)^{1 / \sigma}\right. \\
& \left.+\left[\sum_{j \in \tau^{R}\left(y, W^{L}(y, j), j\right) \geq 0} \exp \left(\frac{\left(y-\tau_{j}^{R} b_{j}^{R}\right)^{1-\gamma}}{1-\gamma}+\beta E_{y^{\prime} \mid y} \mathbf{V}^{\mathbf{G}}\left(y^{\prime}, 1, b_{j}^{R}, m_{j}^{R}\right)\right)^{\frac{1}{\rho \sigma}}\right]^{\rho}\right] \\
& +(1-\lambda) \sigma \log \left[\exp \left(\frac{(y)^{1-\gamma}}{1-\gamma}+\beta E_{y^{\prime} \mid y} \mathbf{V}^{\mathbf{R}}\left(\min \left\{y^{\prime}, \pi^{R}\right\}, b_{i}, m_{i}\right)\right)^{1 / \sigma}\right. \\
& \left.+\left[\sum_{j \in \tau^{R}\left(y, W^{S}(y, j), j\right) \geq 0} \exp \left(\frac{\left(y-\tau_{j}^{R} b_{j}^{R}\right)^{1-\gamma}}{1-\gamma}+\beta E_{y^{\prime} \mid y^{b}} \mathbf{V}^{\mathbf{G}}\left(y^{\prime}, 1, b_{j}^{R}, m_{j}^{R}\right)\right)^{\frac{1}{\rho \sigma}}\right]^{\rho}\right] .
\end{aligned}
$$

${ }^{34}$ The next subsection contains the proofs on how the expectation of the maximum in these expressions is derived. 
Note that in contrast to the previous expressions, now the ex ante value functions do not have a max operator. Under the specific distributional assumptions, the expectation of the maximum over different choices results in the standard log-sum of exponentials widely used in dynamic discrete choice models. These expressions are sometimes referred to as the inclusive values.

In addition, we can characterize the probability of default as

$\mathbf{D}\left(y, 0, b_{i}, m_{i}\right)=$

$$
\frac{\exp \left(\frac{\left(\min \left\{y, \pi^{D}\right\}\right)^{1-\gamma}}{1-\gamma}+\beta E_{y^{\prime} \mid \min \left\{y, \pi^{D}\right\}} \mathbf{V}^{\mathbf{R}}\left(\min \left\{y^{\prime}, \pi^{R}\right\}, b_{i}, m_{i}\right)\right)^{1 / \sigma}}{\left(\sum_{j=1}^{\mathcal{J}} \exp \left(\frac{\left(c_{i j}(y)\right)^{1-\gamma}}{1-\gamma}+\beta E_{y^{\prime}, a^{\prime} \mid y, 0} \mathbf{V}^{\mathbf{G}}\left(y^{\prime}, a^{\prime}, b_{j}, m_{j}\right)\right)^{\frac{1}{\rho \sigma}}\right)^{\rho}+\exp \left(\frac{\left(\min \left\{y, \pi^{D}\right\}\right)^{1-\gamma}}{1-\gamma}+\beta E_{y^{\prime} \mid \min \left\{y, \pi^{D}\right\}} \mathbf{V}^{\mathbf{R}}\left(\min \left\{y^{\prime}, \pi^{R}\right\}, b_{i}, m_{i}\right)\right)^{1 / \sigma}} .
$$

Similarly, the probability of choosing a new debt level $b_{j}$ and maturity $m_{j}$ conditional on not defaulting, $\operatorname{Pr}\left(b^{\prime}=b_{j}, m^{\prime}=m_{j} \mid y, a, b_{i}, m_{i}\right) \equiv \mathbf{G}_{y, a, b_{i}, m_{i}}\left(b_{j}, m_{j}\right)$, is

$$
\mathbf{G}_{y, 0, b_{i}, m_{i}}\left(b_{j}, m_{j}\right)=\frac{\exp \left(\frac{\left(c_{i j}(y)\right)^{1-\gamma}}{1-\gamma}+\beta E_{y^{\prime}, a^{\prime} \mid y, 0} \mathbf{V}^{\mathbf{G}}\left(y^{\prime}, a^{\prime}, b_{j}, m_{j}\right)\right)^{\frac{1}{\rho \sigma}}}{\sum_{k=1}^{\mathcal{J}} \exp \left(\frac{\left(c_{j k}(y)\right)^{1-\gamma}}{1-\gamma}+\beta E_{y^{\prime}, a^{\prime} \mid y, 0} \mathbf{V}^{\mathbf{G}}\left(y^{\prime}, a^{\prime}, b_{k}, m_{k}\right)\right)^{\frac{1}{\rho \sigma}}},
$$

which again says that the probability that a borrower selects a new debt maturity portfolio $j$ increases with the value of that particular portfolio. In a rollover shock, borrowers cannot change the portfolio, which is described by the following policy function:

$$
\mathbf{G}_{y, 1, b_{i}, m_{i}}\left(b_{j}, m_{j}\right)= \begin{cases}1, & \text { for } b_{j}=b_{i} ; m_{j}=m_{i}-1 \\ 0, & \text { otherwise }\end{cases}
$$

The probability of choosing a restructured debt level $b_{j}^{R}$ and maturity $m_{j}^{R}$ conditional on restructuring has a very similar expression, but the sum is only over those debt/maturity choices $(j)$ in the sets defined by $\tau^{R}\left(y, W^{L}(y, j), j\right) \geq 0$ and $\tau^{R}\left(y, W^{S}(y, j), j\right) \geq 0$.

In addition, with probability $\lambda$, a borrower in default receives a restructuring offer from lenders. The probability of choosing to exit default and reschedule the debt is $\mathbf{H}^{\mathbf{L}}\left(y, b_{i}, m_{i}\right)=$

$$
\frac{\left[\sum_{j \in \tau^{R}\left(y, W^{L}(y, j), j\right) \geq 0} \exp \left(\frac{\left(y-\tau_{j}^{R} b_{j}^{R}\right)^{1-\gamma}}{1-\gamma}+\beta E_{y^{\prime} \mid y} \mathbf{V}^{\mathbf{G}}\left(y^{\prime}, 1, b_{j}^{R}, m_{j}^{R}\right)\right)^{1 / \rho \sigma}\right]^{\rho}}{\exp \left(\frac{(y)^{1-\gamma}}{1-\gamma}+\beta E_{y^{\prime} \mid y} \mathbf{V}^{\mathbf{R}}\left(\min \left\{y^{\prime}, \pi^{R}\right\}, b_{i}, m_{i}\right)\right)^{\frac{1}{\sigma}}+\left[\sum_{j \in \tau^{R}\left(y, W^{L}(y, j), j\right) \geq 0} \exp \left(\frac{\left(y-\tau_{j}^{R} b_{j}^{R}\right)^{1-\gamma}}{1-\gamma}+\beta E_{y^{\prime} \mid y} \mathbf{V}^{\mathbf{G}}\left(y^{\prime}, 1, b_{j}^{R}, m_{j}^{R}\right)\right)^{1 / \rho \sigma}\right]^{\rho} .}
$$

This depends on both the borrower's current state and the characteristics of the offer. Restructuring offers that provide a high value for the borrower have a greater chance of being accepted. With probability $(1-\lambda)$, the borrower has the 
option to make a restructuring offer that leads to an almost identical expression for $\mathbf{H}^{S}\left(y, b_{i}, m_{i}\right)$ but with the set of all $j$ in $\tau^{R}\left(y, W^{S}(y, j), j\right) \geq 0$ defining the possible debt/maturity choices.

Finally, the price of a bond in good standing is

$$
\begin{aligned}
q\left(y, a, b_{j}, m_{j} ; m_{i}\right) & \\
=\frac{1}{1+r} E_{y^{\prime}, a^{\prime} \mid y, a} & {\left[\left(1-\mathbf{D}\left(y^{\prime}, a^{\prime}, b_{j}, m_{j}\right)\right)\right.} \\
\times & {\left[1+\sum_{k=1}^{\mathcal{J}} q\left(y^{\prime}, a^{\prime}, b_{k}, m_{k} ; m_{i}-1\right) \mathbf{G}_{y^{\prime}, a^{\prime}, b_{j}, m_{j}}\left(b_{k}, m_{k}\right)\right] } \\
+ & \left.\mathbf{D}\left(y^{\prime}, a^{\prime}, b_{j}, m_{j}\right) q^{D}\left(\min \left\{y^{\prime}, \pi^{D}\right\}, b_{j}, m_{j} ; m_{i}\right)\right],
\end{aligned}
$$

and the price of a bond in default is

$$
\begin{aligned}
& q^{D}\left(y, b_{j}, m_{j}, m_{i}\right) \\
& =\frac{E_{y^{\prime} \mid y}}{1+r}\left[q^{D}\left(\min \left\{y^{\prime}, \pi^{R}\right\}, b_{j}, m_{j}, m_{i}\right)\right. \\
& \left.\quad+\lambda \mathbf{H}^{L}\left(y^{\prime}, b_{j}, m_{j}\right)\left[\frac{1}{-b_{j}} \frac{q^{*}\left(m_{i}, r^{R}\right)}{q^{*}\left(m_{j}, r^{R}\right)} W^{L}\left(y^{\prime}, b_{j}, m_{j}\right)-q^{D}\left(\min \left\{y^{\prime}, \pi^{R}\right\}, b_{j}, m_{j} ; m_{i}\right)\right]\right] .
\end{aligned}
$$

Expectations: We now show how to obtain the main expressions for the policy and value functions after taking expectations over the $\epsilon$ shocks. To avoid repetition, we only provide the proofs for a subset of the expressions. The rest can be obtained following almost identical steps.

Take the distribution for the shocks $\epsilon$ :

$$
F(\mathbf{x})=\exp \left[-\left(\sum_{j=1}^{\mathcal{J}} \exp \left(-\frac{x_{j}-\mu}{\rho \sigma}\right)\right)^{\rho}-\exp \left(-\frac{x_{\mathcal{J}+1}-\mu}{\sigma}\right)\right] .
$$

Define the partial derivative as $F_{j}(\mathbf{x})=\partial F(\mathbf{x}) / \partial x_{j}$ as

$$
\begin{aligned}
& F_{j}(\mathbf{x}) \\
& =\left\{\begin{array}{cc}
\frac{1}{\sigma} \exp \left(-\left[\sum_{j=1}^{\mathcal{J}} \exp \left(-\frac{x_{j}-\mu}{\rho \sigma}\right)\right]^{\rho}-\exp \left(-\frac{x_{\mathcal{J}+1}-\mu}{\sigma}\right)\right) & \\
\times\left(\sum_{j=1}^{\mathcal{J}} \exp \left(-\frac{x_{j}-\mu}{\rho \sigma}\right)\right)^{\rho-1} \exp \left(-\frac{x_{j}-\mu}{\rho \sigma}\right), & \text { for } j=1, \ldots, \mathcal{J} ; \\
\frac{1}{\sigma} \exp \left(-\left[\sum_{j=1}^{\mathcal{J}} \exp \left(-\frac{x_{j}-\mu}{\rho \sigma}\right)\right]^{\rho}-\exp \left(-\frac{x_{\mathcal{J}+1}-\mu}{\sigma}\right)\right) & \\
\quad \times \exp \left(-\frac{x_{\mathcal{J}+1}-\mu}{\sigma}\right), & \text { for } j=\mathcal{J}+1 .
\end{array}\right.
\end{aligned}
$$


In what follows, we omit the state variables $y$ and $a$ to simplify the notation. In addition, let

$\Upsilon_{i, j}$

$$
= \begin{cases}\frac{\left(c_{i j}(y)\right)^{1-\gamma}}{1-\gamma}+\beta E_{y^{\prime}, a \mid y, a} \mathbf{V}^{\mathbf{G}}\left(y^{\prime}, a^{\prime}, b_{j}, m_{j}\right), & \text { for } j=1, \ldots, \mathcal{J} ; \\ \frac{\left(\min \left\{y, \pi^{D}\right\}\right)^{1-\gamma}}{1-\gamma}+\beta E_{y^{\prime} \mid \min \left\{y, \pi^{D}\right\}} \mathbf{V}^{\mathbf{R}}\left(\min \left\{y^{\prime}, \pi^{R}\right\}, b_{i}, m_{i}\right), & \text { for } j=\mathcal{J}+1 .\end{cases}
$$

Also, call $\mathbf{D}_{i}=\mathbf{D}\left(\min \left\{y, \pi^{D}\right\}, a, b_{i}, m_{i}\right)$. Then, the probability of default is

$$
\begin{array}{r}
\mathbf{D}_{i}=\int_{-\infty}^{\infty} F_{\mathcal{J}+1}\left(\Upsilon_{i, \mathcal{J}+1}+\epsilon_{\mathcal{J}+1}-\Upsilon_{i, 1}, \ldots, \Upsilon_{i, \mathcal{J}+1}+\epsilon_{\mathcal{J}+1}-\Upsilon_{i, \mathcal{J}}, \epsilon_{\mathcal{J}+1}\right) d \epsilon_{\mathcal{J}+1} \\
=\frac{1}{\sigma} \int_{-\infty}^{\infty} \exp \left(-\left[\sum_{j=1}^{\mathcal{J}} \exp \left(-\frac{\Upsilon_{i, \mathcal{J}+1}+\epsilon_{\mathcal{J}+1}-\Upsilon_{i, j}-\mu}{\rho \sigma}\right)\right]^{\rho}-\exp \left(-\frac{\epsilon_{\mathcal{J}+1}-\mu}{\sigma}\right)\right) \\
\times \frac{1}{\sigma} \int_{-\infty}^{\infty} \exp \left(-\exp \left(-\frac{\epsilon_{\mathcal{J}+1}-\mu}{\sigma}\right) d \epsilon_{\mathcal{J}+1}\right. \\
\times\left[\sum_{j=1}^{\mathcal{J}} \exp \left(-\frac{\epsilon_{\mathcal{J}+1}-\mu}{\sigma}\right)\right. \\
\left.\left.\left.\quad \Upsilon_{i, \mathcal{J}+1}-\Upsilon_{i, j}\right)\right]^{\rho}-\exp \left(-\frac{\epsilon_{\mathcal{J}+1}-\mu}{\sigma}\right)\right) \\
\times \exp \left(-\frac{\epsilon_{\mathcal{J}+1}-\mu}{\sigma}\right) d \epsilon_{\mathcal{J}+1} .
\end{array}
$$

Call $\exp \left(\phi_{i}\right)=1+\left[\sum_{j=1}^{\mathcal{J}} \exp \left(-\frac{\Upsilon_{i, \mathcal{J}+1}-\Upsilon_{i, j}}{\rho \sigma}\right)\right]^{\rho}$. Then

$$
\begin{aligned}
\mathbf{D}_{i}= & \frac{\exp \left(-\phi_{i}\right)}{\sigma} \\
& \times \underbrace{\int_{-\infty}^{\infty} \exp \left(-\exp \left(-\frac{\epsilon_{\mathcal{J}+1}-\mu-\sigma \phi_{i}}{\sigma}\right)\right) \exp \left(-\frac{\epsilon_{\mathcal{J}+1}-\mu-\sigma \phi_{i}}{\sigma}\right) d \epsilon_{\mathcal{J}+1}}_{=\sigma} \\
= & \frac{1}{1+\left[\sum_{j=1}^{\mathcal{J}} \exp \left(-\frac{\Upsilon_{i, \mathcal{J}+1}-\Upsilon_{i, j}}{\rho \sigma}\right)\right]^{\rho}} \cdot
\end{aligned}
$$


After proper substitution of the definition of $\Upsilon_{i, j}$ and $\Upsilon_{i, \mathcal{J}+1}$, we get the expression for the probability of default described in the previous subsection: $\mathbf{G}_{i j}=\mathbf{G}_{y, a, b_{i}, m_{i}}\left(b_{j}, m_{j}\right)$. Then, the probability of choosing the maturity $/ \mathrm{debt}$ portfolio $j$, conditional on not defaulting, is

$$
\begin{aligned}
& \mathbf{G}_{i, j}=\frac{1}{\left(1-\mathbf{D}_{i}\right)} \int_{-\infty}^{\infty} F_{j}\left(\Upsilon_{i, j}+\epsilon_{j}-\Upsilon_{i, 1}, \ldots, \Upsilon_{i, j}+\epsilon_{j}-\Upsilon_{\mathcal{J}}, \Upsilon_{i, j}+\epsilon_{j}-\Upsilon_{\mathcal{J}+1}\right) d \epsilon_{j} \\
& =\frac{1}{\sigma\left(1-\mathbf{D}_{i}\right)} \int_{-\infty}^{\infty} \exp \left(-\left[\sum_{k=1}^{\mathcal{J}} \exp \left(-\frac{\Upsilon_{i, j}+\epsilon_{j}-\Upsilon_{i, k}-\mu}{\rho \sigma}\right)\right]^{\rho}\right. \\
& \left.-\exp \left(-\frac{\Upsilon_{i, j}+\epsilon_{j}-\Upsilon_{i, \mathcal{J}+1}-\mu}{\sigma}\right)\right) \\
& \times\left(\sum_{k=1}^{\mathcal{J}} \exp \left(-\frac{\Upsilon_{i, j}+\epsilon_{j}-\Upsilon_{i, k}-\mu}{\rho \sigma}\right)\right)^{\rho-1} \exp \left(-\frac{\epsilon_{j}-\mu}{\rho \sigma}\right) d \epsilon_{j} \\
& =\frac{1}{\sigma\left(1-\mathbf{D}_{i}\right)} \int_{-\infty}^{\infty} \exp \left(-\exp \left(-\frac{\epsilon_{j}-\mu}{\sigma}\right)\left[\left[\sum_{k=1}^{\mathcal{J}} \exp \left(-\frac{\Upsilon_{i, j}-\Upsilon_{i, k}}{\rho \sigma}\right)\right]^{\rho}\right.\right. \\
& \left.\left.+\exp \left(-\frac{\Upsilon_{i, j}-\Upsilon_{i, \mathcal{J}+1}}{\sigma}\right)\right]\right) \\
& \times \exp \left(-\frac{\epsilon_{j}-\mu}{\rho \sigma}\right)^{\rho-1}\left(\sum_{k=1}^{\mathcal{J}} \exp \left(-\frac{\Upsilon_{i, j}-\Upsilon_{i, k}}{\rho \sigma}\right)\right)^{\rho-1} \exp \left(-\frac{\epsilon_{j}-\mu}{\rho \sigma}\right) d \epsilon_{j} \\
& =\frac{\left(\sum_{k=1}^{\mathcal{J}} \exp \left(-\frac{\Upsilon_{i, j}-\Upsilon_{i, k}}{\rho}\right)\right)^{\rho-1}}{\sigma\left(1-\mathbf{D}_{i}\right)} \\
& \times \int_{-\infty}^{\infty} \exp \left(-\exp \left(-\frac{\epsilon_{j}-\mu}{\sigma}\right)\left[\left[\sum_{k=1}^{\mathcal{J}} \exp \left(-\frac{\Upsilon_{i, j}-\Upsilon_{i, k}}{\rho \sigma}\right)\right]^{\rho}\right.\right. \\
& \left.\left.+\exp \left(-\frac{\Upsilon_{i, j}-\Upsilon_{i, \mathcal{J}+1}}{\sigma}\right)\right]\right) \\
& \times \exp \left(-\frac{\epsilon_{j}-\mu}{\sigma}\right) d \epsilon_{j}
\end{aligned}
$$


Call $\exp \left(\eta_{i, j}\right)=\left[\sum_{k=1}^{\mathcal{J}} \exp \left(-\frac{\Upsilon_{i, j}-\Upsilon_{i, k}}{\rho \sigma}\right)\right]^{\rho}+\exp \left(\frac{\Upsilon_{i, \mathcal{J}+1}-\Upsilon_{i, j}}{\sigma}\right)$, then

$$
\begin{aligned}
\mathbf{G}_{i, j}= & \frac{\left(\sum_{k=1}^{\mathcal{J}} \exp \left(-\frac{\Upsilon_{i, j}-\Upsilon_{i, k}}{\rho \sigma}\right)\right)^{\rho-1}}{\left(1-\mathbf{D}_{i}\right) \sigma \exp \left(\eta_{i, j}\right)} \\
& \times \underbrace{\int_{-\infty}^{\infty} \exp \left(-\exp \left(-\frac{\epsilon_{j}-\mu-\sigma \eta_{i, j}}{\sigma}\right)\right) \exp \left(-\frac{\epsilon_{j}-\mu-\sigma \eta_{i, j}}{\sigma}\right) d \epsilon_{j}}_{=\sigma} .
\end{aligned}
$$

Since $\left(1-\mathbf{D}_{i}\right) \exp \left(\eta_{i, j}\right)=\left(\sum_{k=1}^{\mathcal{J}} \exp \left(\frac{\Upsilon_{i, k}-\Upsilon_{i, j}}{\rho \sigma}\right)\right)^{\rho}$, we have that

$$
\mathbf{G}_{i, j}=\frac{1}{\sum_{k=1}^{\mathcal{J}} \exp \left(\frac{\Upsilon_{i, k}-\Upsilon_{i, j}}{\rho \sigma}\right)},
$$

which, after proper substitution of the definition of $\Upsilon_{i, j}$ and $\Upsilon_{i, k}$, gives the expression for the probability of choosing the maturity/debt portfolio $j$ described in the previous subsection.

Finally, call $\mathbf{V}_{i}^{\mathbf{G}}=\mathbf{V}^{\mathbf{G}}\left(y, a, b_{i}, m_{i}\right)$. We can find $\mathbf{V}_{i}^{\mathbf{G}}=E_{\boldsymbol{\epsilon}}\left[\max _{j \in\{1, \ldots, \mathcal{J}+1\}}\left\{\Upsilon_{i, j}\right.\right.$ $\left.\left.+\epsilon_{j}\right\}\right]$ in the following way:

$$
\begin{aligned}
& \mathbf{V}_{i}^{\mathbf{G}}=\sum_{j=1}^{\mathcal{J}+1} \int_{-\infty}^{\infty}\left(\mathbf{\Upsilon}_{i, j}+\epsilon_{j}\right) \\
& \times F_{j}\left(\Upsilon_{i, j}+\epsilon_{j}-\Upsilon_{i, 1}, \ldots, \Upsilon_{i, j}+\epsilon_{j}-\Upsilon_{i, \mathcal{J}}, \Upsilon_{i, j}+\epsilon_{j}-\Upsilon_{i, \mathcal{J}+1}\right) d \epsilon_{j} \\
& =\frac{1}{\sigma} \sum_{j=1}^{\mathcal{J}} \int_{-\infty}^{\infty}\left(\Upsilon_{i, j}+\epsilon_{j}\right) \exp \left(-\left[\sum_{k=1}^{\mathcal{J}} \exp \left(-\frac{\Upsilon_{i, j}+\epsilon_{j}-\Upsilon_{i, k}-\mu}{\rho \sigma}\right)\right]^{\rho}\right. \\
& \left.-\exp \left(-\frac{\Upsilon_{i, j}+\epsilon_{j}-\Upsilon_{i, \mathcal{J}+1}-\mu}{\sigma}\right)\right) \\
& \times\left(\sum_{k=1}^{\mathcal{J}} \exp \left(-\frac{\Upsilon_{i, j}+\epsilon_{j}-\Upsilon_{i, k}-\mu}{\rho \sigma}\right)\right)^{\rho-1} \exp \left(-\frac{\epsilon_{j}-\mu}{\rho \sigma}\right) d \epsilon_{j} \\
& +\frac{1}{\sigma} \int_{-\infty}^{\infty}\left(\Upsilon_{i, \mathcal{J}+1}+\epsilon_{\mathcal{J}+1}\right) \exp \left(-\left[\sum_{k=1}^{\mathcal{J}} \exp \left(-\frac{\Upsilon_{i, \mathcal{J}+1}+\epsilon_{\mathcal{J}+1}-\Upsilon_{i, k}-\mu}{\rho \sigma}\right)\right]^{\rho}\right. \\
& \left.-\exp \left(-\frac{\epsilon_{\mathcal{J}+1}-\mu}{\sigma}\right)\right) \\
& \times \exp \left(-\frac{\epsilon_{\mathcal{J}+1}-\mu}{\sigma}\right) d \epsilon_{\mathcal{J}+1}
\end{aligned}
$$




$$
\begin{aligned}
= & \sum_{j=1}^{\mathcal{J}} \exp \left(-\eta_{i, j}\right)\left(\sum_{k=1}^{\mathcal{J}} \exp \left(-\frac{\Upsilon_{i, j}-\Upsilon_{i, k}}{\rho \sigma}\right)\right)^{\rho-1} \\
& \times\left[\Upsilon_{i, j}+\mu+\sigma \eta_{i, j}\right. \\
& +\underbrace{\int_{-\infty}^{\infty}\left(\frac{\epsilon_{j}-\mu-\sigma \eta_{i, j}}{\sigma}\right) \exp \left(-\exp \left(-\frac{\epsilon_{j}-\mu-\sigma \eta_{i, j}}{\sigma}\right)\right) \exp \left(-\frac{\epsilon_{j}-\mu-\sigma \eta_{i, j}}{\sigma}\right) d \epsilon_{\mathcal{J}+1}}_{-\infty}] \\
& +\exp \left(-\phi_{i}\right)\left[\Upsilon_{i, \mathcal{J}+1}+\mu+\sigma \phi_{i}\right. \\
+ & \underbrace{\int_{-\infty}^{\infty}\left(\frac{\epsilon_{\mathcal{J}+1}-\mu-\sigma \phi_{i}}{\sigma}\right) \exp \left(-\exp \left(-\frac{\epsilon_{\mathcal{J}+1}-\mu-\sigma \phi_{i}}{\sigma}\right)\right) \exp \left(-\frac{\epsilon_{\mathcal{J}+1}-\mu-\sigma \phi_{i}}{\sigma}\right) d \epsilon_{\mathcal{J}+1}}_{-\infty}],
\end{aligned}
$$

where $\gamma \approx 0.5772$ is Euler's constant. Making $\mu=-\sigma \gamma$, the previous expression simplifies to

$$
\begin{aligned}
\mathbf{V}_{i}^{\mathbf{G}}= & \sum_{j=1}^{\mathcal{J}}\left[\exp \left(-\eta_{i, j}\right)\left(\sum_{k=1}^{\mathcal{J}} \exp \left(-\frac{\Upsilon_{i, j}-\Upsilon_{i, k}}{\rho \sigma}\right)\right)^{\rho-1}\left[\Upsilon_{i, j}+\sigma \eta_{i, j}\right]\right] \\
& +\exp \left(-\phi_{i}\right)\left[\Upsilon_{i, \mathcal{J}+1}+\sigma \phi_{i}\right] .
\end{aligned}
$$

Note that

$$
\exp \left(-\phi_{i}\right)\left[\Upsilon_{i, \mathcal{J}+1}+\sigma \phi_{i}\right]=\frac{\Upsilon_{i, \mathcal{J}+1}+\sigma \log \left[1+\left(\sum_{k=1}^{\mathcal{J}} \exp \left(-\frac{\Upsilon_{i, \mathcal{J}+1}-\Upsilon_{i, k}}{\rho \sigma}\right)\right)^{\rho}\right]}{1+\left(\sum_{k=1}^{\mathcal{J}} \exp \left(-\frac{\Upsilon_{i, \mathcal{J}+1}-\Upsilon_{i, k}}{\rho \sigma}\right)\right)^{\rho}},
$$

and also,

$$
\begin{aligned}
& \exp \left(-\eta_{i, j}\right)\left(\sum_{k=1}^{\mathcal{J}} \exp \left(-\frac{\Upsilon_{i, j}-\Upsilon_{i, k}}{\rho \sigma}\right)\right)^{\rho-1}\left[\Upsilon_{i, j}+\sigma \eta_{i, j}\right] \\
& =\frac{\left(\sum_{k=1}^{\mathcal{J}} \exp \left(-\frac{\Upsilon_{i, \mathcal{J}+1}-\Upsilon_{i, k}}{\rho \sigma}\right)\right)^{\rho-1}\left[\Upsilon_{i, \mathcal{J}+1}+\sigma \log \left[1+\left(\sum_{k=1}^{\mathcal{J}} \exp \left(-\frac{\Upsilon_{i, \mathcal{J}+1}-\Upsilon_{i, k}}{\rho \sigma}\right)\right)^{\rho}\right]\right]}{\exp \left(-\frac{\Upsilon_{i, j}-\Upsilon_{i, \mathcal{J}+1}}{\sigma}\right)\left[1+\left(\sum_{k=1}^{\mathcal{J}} \exp \left(-\frac{\Upsilon_{i, \mathcal{J}+1}-\Upsilon_{i, k}}{\rho \sigma}\right)\right)^{\rho}\right]}
\end{aligned}
$$


Then, the value is

$$
\begin{aligned}
\mathbf{V}_{i}^{\mathbf{G}}= & {\left[\boldsymbol{\Upsilon}_{i, \mathcal{J}+1}+\sigma \log \left[1+\left(\sum_{k=1}^{\mathcal{J}} \exp \left(-\frac{\Upsilon_{i, \mathcal{J}+1}-\Upsilon_{i, k}}{\rho \sigma}\right)\right)^{\rho}\right]\right] } \\
& \times \frac{1}{1+\left(\sum_{k=1}^{\mathcal{J}} \exp \left(-\frac{\Upsilon_{i, \mathcal{J}+1}-\Upsilon_{i, k}}{\rho \sigma}\right)\right)^{\rho}} \\
& \times\left(1+\sum_{j=1}^{\mathcal{J}} \frac{\left(\sum_{k=1}^{\mathcal{J}} \exp \left(-\frac{\Upsilon_{i, \mathcal{J}+1}-\Upsilon_{i, k}}{\rho \sigma}\right)\right)^{\rho-1} \exp \left(\frac{\Upsilon_{i, \mathcal{J}+1}-\Upsilon_{i, j}}{\rho \sigma}\right)^{\rho-1}}{\rho \Upsilon_{i, \mathcal{J}+1}-\Upsilon_{i, j}}\right)^{\rho} \\
= & \Upsilon_{i, \mathcal{J}+1}+\sigma \exp \left[1+\left(\sum_{k=1}^{\mathcal{J}} \exp \left(-\frac{\Upsilon_{i, \mathcal{J}+1}-\Upsilon_{i, k}}{\rho \sigma}\right)\right)^{\rho}\right],
\end{aligned}
$$

which, after proper substitution of the definition of $\Upsilon_{i, k}$ and $\Upsilon_{i, \mathcal{J}+1}$, gives the expression for the ex ante lifetime utility described in the previous subsection.

\section{REFERENCES}

Aguiar, Mark, Manuel Amador, Hugo Hopenhayn, and Iván Werning. 2019. "Take the Short Route: Equilibrium Default and Debt Maturity." Econometrica 87 (2): 423-62.

-Aguiar, Mark, and Gita Gopinath. 2006. "Defaultable Debt, Interest Rates and the Current Account." Journal of International Economics 69 (1): 64-83.

Amador, Manuel, and Christopher Phelan. 2018. "Reputation and Sovereign Default." NBER Working Paper 24682.

-Arellano, Cristina. 2008. "Default Risk and Income Fluctuations in Emerging Economies." American Economic Review 98 (3): 690-712.

Arellano, Cristina, Yan Bai, and Luigi Bocola. 2017. "Sovereign Default Risk and Firm Heterogeneity.” NBER Working Paper 23314.

Arellano, Cristina, Xavier Mateos-Planas, and José-Víctor Ríos-Rull. 2019. "Partial Default.” NBER Working Paper 26076.

Arellano, Cristina, and Ananth Ramanarayanan. 2012. "Default and the Maturity Structure in Sovereign Bonds." Journal of Political Economy 120 (2): 187-232.

Asonuma, Tamon, and Hyungseok Joo. 2017. "Sovereign Debt Restructurings: Delays in Renegotiations and Risk Averse Creditors." https://papers.ssrn.com/sol3/papers.cfm?abstract_id=2897145.

Asonuma, Tamon, and Christoph Trebesch. 2016. "Sovereign Debt Restructurings: Preemptive or Post-Default." Journal of the European Economic Association 14 (1): 175-214.

Benjamin, David, and Mark L.J. Wright. 2013. "Recovery before Redemption: A Theory of Delays in Sovereign Debt Renegotiations." http://www.acsu.buffalo.edu/ db64/2013-11-11\%20Econometrica_1.pdf.

- Benjamin, David, and Mark L.J. Wright. 2018. "Deconstructing Delays in Sovereign Debt Restructuring." Oxford Economic Papers 71 (2): 382-404.

- Bianchi, Javier. 2016. "Efficient Bailouts?" American Economic Review 106 (12): 3607-59.

Blundell-Wignall, Adrian, and Patrick Slovik. 2010."The EU Stress Test and Sovereign Debt Exposures." OECD Finance, Insurance and Private Pensions Working Paper 4.

Brutti, Filippo, and Philip Sauré. 2013."Repatriation of Debt in the Euro Crisis: Evidence for the Secondary Market Theory." Schweizerische National Bank Working Paper 3/2014.

Caliendo, Lorenzo, Maximiliano Dvorkin, and Fernando Parro. 2019. "Trade and Labor Market Dynamics: General Equilibrium Analysis of the China Trade Shock." Econometrica 87 (3): 741-835. 
Chatterjee, Satyajit, Dean Corbae, Kyle P. Dempsey, and José-Víctor Ríos-Rull. 2016. "A Theory of Credit Scoring and the Competitive Pricing of Default Risk." Unpublished.

Chatterjee, Satyajit, and Burcu Eyigungor. 2012. "Maturity, Indebtedness and Default Risk." American Economic Review 102 (6): 2674-99.

Comelli, Fabio. 2015. "Estimation and Out-of-Sample Prediction of Sudden Stops: Do Regions of Emerging Markets Behave Differently from Each Other?" International Monetary Fund Working Paper 15/138.

Corsetti, Giancarlo, Aitor Erce, and Timothy Uy. 2018. "Debt Sustainability and the Terms of Official Support." CEPR Discussion Paper DP13292.

Cruces, Juan J., and Christoph Trebesch. 2013. "Sovereign Defaults: The Price of Haircuts." American Economic Journal: Macroeconomics 5 (3): 85-117.

Das, Udaibir S., Michael G. Papaioannou, and Christoph Trebesch. 2012. "Sovereign Debt Restructurings 1950-2010: Literature Survey, Data, and Stylized Facts.” International Monetary Fund Working Paper $12 / 203$.

Dvorkin, Maximiliano, Juan M. Sánchez, Horacio Sapriza, and Emircan Yurdagul. 2021. "Replication data for: Sovereign Debt Restructurings." American Economic Association [publisher], Inter-university Consortium for Political and Social Research [distributor]. https://doi.org/10.3886/ E115905V1.

Eaton, Jonathan, and Mark Gersovitz. 1981. "Debt with Potential Repudiation: Theoretical and Empirical Analysis." Review of Economic Studies 48 (2): 289-309.

Feenstra, Robert C., Robert Inklaar, and Marcel P. Timmer. 2015. "The Next Generation of the Penn World Table." American Economic Review 105 (10): 3150-82.

Fernández, Raquel, and Alberto Martin. 2014. "The Long and the Short of It: Sovereign Debt Crises and Debt Maturity." NBER Working Paper 20786.

Ffrench-Davis, Ricardo, and Robert Devlin. 1993. "Diez Años de la Crisis de la Deuda Latinoamericana." Comercio Exterior 43 (1): 4-20.

Guttentag, Jack M., and Richard Herring. 1989. "Accounting for Losses on Sovereign Debt: Implications for New Lending." Essays in International Finance 172: 1-45.

-Hatchondo, Juan Carlos, and Leonardo Martinez. 2009. "Long-Duration Bonds and Sovereign Defaults." Journal of International Economics 79 (1): 117-25.

-Hatchondo, Juan Carlos, Leonardo Martinez, and César Sosa-Padilla. 2014. "Voluntary Sovereign Debt Exchanges." Journal of Monetary Economics 61: 32-50.

-Hatchondo, Juan Carlos, Leonardo Martinez, and César Sosa-Padilla. 2016. "Debt Dilution and Sovereign Default Risk.” Journal of Political Economy 124 (5): 1383-1422.

International Monetary Fund (IMF). 2014. The Fund's Lending Framework and Sovereign DebtPreliminary Considerations. Washington, DC: IMF.

International Monetary Fund (IMF). 2019. International Financial Statistics. IMF Data. https://data. imf.org/?sk=4C514D48-B6BA-49ED-8AB9-52B0C1A0179B (accessed December 2019).

Joffe, Marc. 2015. Doubly Bound: The Costs of Issuing Municipal Bonds. Berkeley, CA: Haas Institute for a Fair and Inclusive Society.

-Lizarazo, Sandra Valentina. 2013. "Default Risk and Risk Averse International Investors." Journal of International Economics 89 (2): 317-30.

Lopez, Jose A. 2001. “Federal Reserve Banks' Imputed Cost of Equity Capital.” Federal Reserve Bank of San Francisco Economic Letter 2001-23.

McFadden, Daniel L. 1978. "Modelling the Choice of Residential Location." In Spatial Interaction Theory and Residential Location, edited by A. Karlquist, et al., 75-96. Amsterdam: Elsevier.

-Mendoza, Enrique G., and Vivian Z. Yue. 2012. "A General Equilibrium Model of Sovereign Default and Business Cycles." Quarterly Journal of Economics 127 (2): 889-946.

Mihalache, Gabriel. 2017. "Sovereign Default Resolution through Maturity Extension.” Stony Brook University Working Paper 17-08.

Mihalache, Gabriel, and David Wiczer. 2018. "Sovereign Debt Maturity: Stock and Flow Dynamics." Unpublished.

-Miller, Robert A. 1984. "Job Matching and Occupational Choice." Journal of Political Economy 92 (6): 1086-1120.

Pakes, Ariel. 1986. "Patents as Options: Some Estimates of the Value of Holding European Patent Stocks." Econometrica 54 (4): 755-84.

Pouzo, Demian, and Ignacio Presno. 2012. "Sovereign Default Risk and Uncertainty Premia." Federal Reserve Bank of Boston Working Paper 12-11. 
Richmond, Christine, and Daniel A. Dias. 2009. "Duration of Capital Market Exclusion: An Empirical Investigation." https://papers.ssrn.com/sol3/papers.cfm?abstract_id=1027844.

Rieffel, Lex. 2003. Restructuring Sovereign Debt: The Case for Ad Hoc Machinery. Washington, DC: Brookings Institution Press.

Roch, Francisco, and Harald Uhlig. 2016. "The Dynamics of Sovereign Debt Crises and Bailouts." IMF Working Paper 16/136.

- Rust, John. 1987. "Optimal Replacement of GMC Bus Engines: An Empirical Model of Harold Zurcher." Econometrica 55 (5): 999-1033.

-Sachs, Jeffrey S. 1986. "Managing the LDC Debt Crisis." Brookings Papers on Economic Activity 16 (2): 397-440.

Sánchez, Juan M., Horacio Sapriza, and Emircan Yurdagul. 2018. "Sovereign Default and Maturity Choice." Journal of Monetary Economics 95: 72-85.

Sturzenegger, Federico, and Jeromin Zettelmeyer. 2005. "Haircuts: Estimating Investor Losses in Sovereign Debt Restructurings, 1998-2005.” IMF Working Paper 05/137.

Sturzenegger, Federico, and Jeromin Zettelmeyer. 2006. Debt Defaults and Lessons from a Decade of Crises. Cambridge: MIT Press.

-Sunder-Plassmann, Laura. 2018. "Writing Off Sovereign Debt: Default and Recovery Rates over the Cycle." Journal of International Money and Finance 81: 221-41.

- Tomz, Michael, and Mark L.J. Wright. 2013. "Empirical Research on Sovereign Debt and Default." Annual Review of Economics 5: 247-72.

-Wolpin, Kenneth I. 1984. "An Estimable Dynamic Stochastic Model of Fertility and Child Mortality." Journal of Political Economy 92 (5): 852-74.

-Yue, Vivian Z. 2010. "Sovereign Default and Debt Renegotiation." Journal of International Economics 80 (2): 176-87.

Zettelmeyer, Jeromin, Christoph Trebesch, and G. Mitu Gulati. 2013. "The Greek Debt Restructuring: An Autopsy." Economic Policy 28 (75): 513-63. 